\title{
Öğrenci Merkezli Strateji, Yöntem ve Tekniklerin Akademik Başarıya Etkisi: Bir Meta-Analiz Çalışması*
}

\author{
The Effect of Student-Centered Strategies, Methods and \\ Techniques on Academic Achievement: A Meta-Analysis \\ Study
}

\author{
Melis YEŞILILINAR UYAR**, Ahmet DOĞANAY***
}

\begin{abstract}
Öz: Araştırmanın amacı, öğrenci merkezli strateji, yöntem ve tekniklerin akademik başarı üzerindeki etkisini belirlemektir. Meta-analiz yönteminin kullanıldığı araştırmada, dâhil edilme ölçütlerini karşılayan 105 çalışma araştırma kapsamına alınmıştır. Verilerin analizinde CMA yazılımı kullanılarak, Hedges'g ye göre etki büyüklüğü katsayıları hesaplanmıştır. Analiz sonucunda; öğrenci merkezli strateji yöntem ve tekniklerin öğretmen merkezli yaklaşımlara göre farklı derslerdeki akademik başarıyı artırmada çok geniş düzeyde bir etkiye sahip olduğu belirlenmiştir. Bununla birlikte çalışılan konunun yapısının, ölçme aracının özelliklerinin ve kontrol altına alınması gereken öğrenci kaynaklı değişkenlerin, etki büyüklüğü düzeylerini farklılaştırdığı ortaya konmuştur. Ulaşılan bu sonuçlar, farklı derslerin öğretiminde kullanılan öğrenci merkezli yaklaşımların, akademik başarıyı artırmada önemli bir değişken olduğunu göstermektedir. Ancak amaçlara uygun bir öğretim sürecinin gerçekleştirilmesi ve değerlendirilmesi için, strateji yöntem ve tekniğin seçiminden önce; içeriğin, ölçme aracının ve öğrenci özelliklerinin gözden geçirilmesi önerilmektedir.
\end{abstract}

Anahtar Kelimeler: Akademik başarı, meta-analiz, öğrenci merkezli strateji, yöntem ve teknikler

\begin{abstract}
The aim of this study is to determine the effect of student-centered strategies, methods, and techniques on the academic achievement. Meta-analysis method was used in this study. Data of the study were obtained from 105 articles that meet the inclusion criteria. In the analysis of the data, CMA software was preferred, and the effect size coefficients were calculated according to Hedges' $\mathrm{g}$. As a result, it was found out that student-centered strategies, methods and techniques are more effective in increasing the academic achievement in different courses when compared to the teacher-centered approaches, and that this effect is very large. Additionally, it was revealed that the structure of the studied subject, the characteristics of the measurement instrument and the student-derived variables that need to be controlled differentiate the effect size levels. These results show that the student-centered approaches used in the teaching of various subjects are an important variable in increasing the academic achievement. However, for the implementation and evaluation of teaching process suitable for the objectives, it is recommended that the content, the measurement instrument, and the student's characteristics should be considered before choosing strategy, method, and technique.

Keywords: Academic achievement, meta-analysis, student-centered strategies, methods and techniques
\end{abstract}

\section{Giriş}

Bilginin günümüzde artarak çoğalmasıyla, eğitim sürecinde benimsenen felsefi yaklaşımların da değişmeye başladığı görülmektedir. Yaşanan bu değişim, eğitim aracılığıyla kazandırılması hedeflenen bilgi ve becerilerin neler olması gerektiği konusunda birtakım sorgulamaları beraberinde getirmekte ve eğitim programının öğelerine yön vermektedir. Çağın gereksinimleri doğrultusunda yapılandırılan bir eğitim programının; bilgiyi anlama, uygulama ve yeni bilgi

\footnotetext{
*Bu çalışmanın bir bölümü, 26. Uluslararası Eğitim Bilimleri Kongresi’nde sözlü bildiri olarak sunulmuştur (20-23 Nisan 2017, Antalya).

**Dr. Öğretim Üyesi, Dumlupınar Üniversitesi, Eğitim Fakültesi, Kütahya-Türkiye, e-posta: myesilpinaruyar@gmail.com

***Prof. Dr., Çukurova Üniversitesi, Eğitim Fakültesi, Adana-Türkiye, e-posta: adoganay@cu.edu.tr
} 
üretme süreçlerinde öğrenciye rehberlik etmesi gerekmektedir. $\mathrm{Bu}$ süreçte öğretmenlerin sorgulama, eleştirel ve yaratıcı düşünme, problem çözme, bilişsel farkındalık becerileri ile sosyo-duygusal becerilerin kazanımı için uygun fırsatlar sunması gerektiği ifade edilmektedir (Fink, 2016; Marzano, Pickering ve Pollock, 2001; McCombs, 2012; Overby, 2011; Silberman, 1996/2016).

Eğitimin her kademesi için, öğrencilerin gereksinim duydukları bu bilgi ve becerileri kazanmalarında ise bilginin doğrudan öğretiminden ziyade bilginin kalıcılığını sağlamaya yönelik yaklaşımların ön plana çıktığı görülmektedir (Armstrong, 2000; McCombs ve Whisler, 1997; McTighe ve Wiggins, 1999). Bilginin doğrudan öğretimini hedefleyen yaklaşımlarda; yoğun içeriğin daha kısa bir zaman diliminde sunumu gerçekleştirilebilirken, öğrencilerin temel bilgi ve becerileri kazanmaları hedeflenmektedir (Adams ve Carnine, 2003; Morrison, Ross ve Kemp, 2004). Öğretmenin daha aktif rol üstlendiği bu yaklaşımda; sorular, alıştırmalar ve problem durumları aracılığıyla öğrencinin bilgiyi yeni durumlara transfer etmesi ve sürece katılımı sağlanabilmektedir (Senemoğlu, 2007). İlgili araştırmalar da iyi planlanmış ve örneklerle desteklenmiş doğrudan öğretim uygulamalarının kavramsal bilginin gelişimine ve temel becerilerin kazanımına önemli katkılar sağladığını göstermektedir (Botts, Losardo, Tillery ve Werts, 2014; Klahr ve Nigam, 2004; Rittle-Johnson, 2006; Schwartz ve Bransford, 1998).

Öğrenci merkezli yaklaşım, öğrencilerin başarıya ulaşmalarını sağlayan olumlu öğrenme ortamlarının yaratılmasında, gerekli olan faktörleri açıklığa kavuşturan bir temel olarak tanımlanmaktadır (McCombs, 1997, Akt. Brown, 2003). Bu yaklaşımda öğrencilerin, farklı yolları kullanarak ve düşünme süreçlerini işe koşarak bilgiye ulaşmaları hedeflenmektedir. Bu süreçte öğrencilerden bilginin farkına varmaları, örnekler bulmaları ve kendi öğrenme düzeylerine uygun görev ya da etkinlikleri tamamlamaları beklenirken, öğretmenlerin ise öğrenciyi izlemesi ve sürece rehberlik etmesi gerekmektedir (American Psychological Association [APA], 1997; Brown, 2003; Cornelius-White, 2007; McCombs, 2012; Schunk, 2012; Silberman, 1996/2016). Öğrencilere rehberlik sürecinde, öğrencilerin çözüm yoluna ulaşmalarını, çevreyle etkileşim kurmalarını, olay, olgu ve nesnelere çok yönlü bakmalarını sağlayan etkinliklerin kullanımı önerilmektedir (Sönmez, 2009). Öğrenci merkezli öğretim ise, öğrencilerin bireysel gereksinimlerini, tercihlerini ve amaçlarını merkeze alan ve öğrencilerin öğrenmelerini etkileyen karar verme süreçlerine giderek artan bir yapıda katılımlarını sağlayan bir süreç olarak açıklanmaktır (Benson, 2012).

Weimer (2002) öğrenci merkezli bir öğretim sürecinde beş temel özelliğin dikkate alınması gerektiğini belirtmektedir. $\mathrm{Bu}$ süreçte; öncelikle öğrencilerin öğrenmelerine odaklanılması, öğrenmeye ilişkin kararların öğrencilerle birlikte alınması, içeriğin; öğrenme becerilerinin ve öğrencilerin kendilerine ilişkin farkındalıklarının geliştirilmesi amacıyla kullanımı önerilmektedir. Bunun yanı sıra, öğrencileri güdüleyen ve sorumluluk almalarını sağlayan bir öğrenme ortamının yaratılması, değerlendirme etkinliklerinin; öğrenmeyi güçlendirme, öz değerlendirme ve akran değerlendirme becerilerini geliştirmek amacıyla kullanılması gerektiği önemle vurgulanmaktadır (Weimer, 2002). Öğrencileri güdüleyen ve sorumluluk almalarını sağlayan bir öğretme ortamının yaratılmasında ise bu amaca hizmet eden öğretim strateji, yöntem ve tekniklerinin kullanılması gerekmektedir. Tümevarımsal, sosyal ve bağımsız öğretim yaklaşımları olarak genel bir yapıda sınıflandırılan bu yaklaşımlar; öğrencilerin kavramları ve genellemeleri keşfetmelerine yardımcı olan araştırmaları, projeleri, sosyal etkileşimi gerektiren tartışma, işbirliğine dayalı öğrenme, rol oynama gibi yöntem ve teknikleri ve öğrenme merkezleri ve istasyon gibi öğretmen yönlendirmesinin daha da aza indirgendiği teknikleri içerebilmektedir (Tok, 2009). Öğrenciyi merkeze alan ve öğrencinin sürece aktif katılımını sağlayan bu strateji, yöntem ve tekniklerin farklı araştırmalarda kullanılarak incelendiği belirlenmiştir (Asha ve Hawi, 2016; Baş ve Beyhan, 2010; Günter ve Kilınç-Alpat, 2017; Kılınçaslan ve Özdemir-Şimşek, 2015; Rizi, Najafipour, Haghani ve Dehghan, 2013; Thoron ve Myers, 2012; Tran ve Lewis, 2012; Yang ve Chang, 2013).

Öğrenci merkezli eğitim her ne kadar öğrencinin anlamlı öğrenmesi için etkili yollar sunsa da her koşulda kullanımı uygun değildir. Bu süreçte öğrenci özellikleri, öğrenme kazanımları, konunun yapısı, sınıf ortamının koşulları gibi farklı etmenlerin dikkate alınması 
gerektiği belirtilmektedir (Morrison ve diğerleri, 2004). Belirtilen noktalar doğrultusunda öğrenci merkezli yaklaşımlar altında yer alan strateji, yöntem ve tekniklerin de çeşitlilik gösterdiği, bu süreçte öğretmen-öğrenci arasında kurulan iletişimin, öğretmenlerin öğrenci merkezli yaklaşıma yönelik inançlarının strateji, yöntem ve tekniklerin kullanım ilkelerinin ve sıklığının; akademik başarı, motivasyon, tutum vb. değişkenlerin gelişimini etkilediği görülmektedir (Cheang, 2009; Cornelius-White, 2007; Hattie, 2009; Pedersen ve Liu, 2003). Eğitim araştırmalarına konu alan bu değişkenler güncel eğilimler ışığında değişiklik gösterse de akademik başarının kavramsal anlamaya ilişsin somut veriler sunan önemli bir değişken olduğu belirtilmektedir (Hattie, 2009; Rivkin, Hanushek ve Kain, 2005; Savelsbergh ve diğerleri, 2016).

Konuyla ilgili araştırmalarda ise öğrenci merkezli strateji, yöntem ve teknikler kapsamında yer alan işbirliğine dayalı öğrenme (Biçer, 2017; Capar ve Tarım, 2015; Jonhnson, Johnson ve Stanne, 2000; Kyndt ve diğerleri, 2013; Savelsbergh ve diğerleri, 2016; Schroeder, Scott, Tolson, Huang ve Lee, 2007; Springer, Stanne ve Donovan, 1999; Şen ve Y1lmaz, 2013; Tuncer ve Dikmen, 2017), sorgulama temelli öğrenme (Lazonder ve Harmsen, 2016; Savelsbergh ve diğerleri, 2016), probleme dayalı (Ayaz, 2015; Vernon ve Blake 1993; Zhou ve diğerleri, 2016) ve proje tabanlı öğrenme (Ayaz ve Söylemez, 2015) gibi öğrenci merkezli yöntemlerin akademik başarı üzerindeki etkisinin meta-analiz yöntemi kullanılarak incelendiği belirlenmiş̧ir. Araştırmaların sonuçları; işbirliğine dayalı öğrenme, sorgulama temelli öğrenme, probleme dayalı öğrenme ve proje tabanlı öğrenme gibi öğretim yöntemlerinin, akademik başarıyı artırmada öğretmen merkezli yaklaşımlara göre daha etkili olduğunu göstermektedir. Diğer bir boyutta öğrenci merkezli uygulamaları temel alan yapılandırmacı yaklaşımın (Ayaz ve Şekerci, 2015; Semerci ve Batdi, 2015; Ural ve Bümen, 2016), sosyal bilgiler derslerinde kullanılan öğrenci merkezli öğrenme-öğretme süreçlerinin (Yaşar, Çengelci-Köse, Göz ve Gürdoğan-Bayır, 2015), matematik derslerinde kullanılan alternatif ve öğrenci merkezli yöntemlerin (Çelik, 2013; Topan, 2013) ve öğrenci merkezli öğretmen-öğrenci ilişkilerinin (Cornelius-White, 2007) akademik başarı üzerindeki etkisinin belirlendiği görülmektedir. $\mathrm{Bu}$ çalışmalarda; öğrenci merkezli uygulamaların, akademik başarı üzerinde geniş (Çelik, 2013; Semerci ve Batdi, 2015; Topan, 2013; Ural ve Bümen, 2016) ve çok geniş (Ayaz ve Şekerci, 2015; Yaşar ve diğerleri, 2015) düzeyde etkiye sahip olduğu belirlenmiştir.

Araştırma sonuçları öğrenci merkezli strateji, yöntem ve tekniklerin etkisine yönelik önemli veriler sunmakla birlikte, bu konuda önerilen eğitim araştırmalarında genel eğilimi ortaya koyan çalışmalar yapılmasıdır (Hattie, 2009; Hedges, 1987). Diğer bir ifadeyle tek bir araştırmanın ya da birkaç araştırmanın sonucunun, bir strateji ya da yaklaşımın işe yarayıp yaramadığ konusunda belirleyici olamayacağ 1 , bulguların sentezlenmiş sonuçlarının o konuyla ilgili bilinen en iyi sonuçlar olarak kabul edilmesi gerektiği belirtilmektedir (Marzano ve diğerleri, 2001).

Belirtilen noktaların 1şığında, öğrenci merkezli strateji, yöntem ve tekniklerin bütüncül bir yapıda ele alınmasıyla, bu strateji, yöntem ve tekniklerin akademik başarı üzerindeki etkisinin kapsamlı ve karşılaştırmalı incelenmesine gereksinim duyulmuştur. Bu gereksinim doğrultusunda gerçekleştirilen araştırmada, farklı çalışmalarda kullanılan öğrenci merkezli strateji, yöntem ve tekniklerin akademik başarı üzerindeki etkisinin belirlenmesi amaçlanmıştır.

$\mathrm{Bu}$ amaç doğrultusunda aşağıda belirtilen sorulara yanıt aranmıştır:

- Akademik başarıyı artırmak için hangi öğrenci merkezli strateji, yöntem ve teknikler kullanılmıştır?

- Öğrenci merkezli strateji, yöntem ve tekniklerin, öğretmen merkezli yaklaşımlara göre öğrencilerin akademik başarısı üzerindeki etkisi nedir?

- Etki büyüklügüü düzeylerinin farklılaşmasına neden olan etmenler nelerdir?

Araştırmadan elde edilen sonuçların, öğrenci merkezli uygulamaların programlardaki yeri, önemi ve etkili kullanım ilkeleri konularında, program geliştirme çalışmalarının 
iyileştirilmesine katkı sağlaması beklenmektedir. Bunun yanı sıra ulaşılan sonuçların; öğrenci merkezli uygulamaların etkili bir şekilde gerçekleştirilmesi sürecinde eğitimcilere yol gösterici nitelikte olacağı düşünülmektedir.

\section{Yöntem}

\section{Araştırma modeli}

Araştırmada meta-analiz yöntemi kullanılmıştır. Meta-analiz, belirli bir tekniğin ortalama etkisini belirlemeyi amaçlamakta ve farklı araştırma sonuçlarını birleştirmektedir (Borenstein, Hedges, Higgins ve Rothstein, 2009; Marzano ve diğerleri, 2001). Meta-analiz yaparken, araştırmacı çalışmaların sonuçlarını etki büyüklüğü adı verilen bir ölçü birimine çevirmektedir (Marzano ve diğerleri, 2001). Bu doğrultuda meta-analiz yöntemi; bir konu, tema ya da çalışma alanı kapsamındaki benzer çalışmaların, belirli ölçütler altında gruplanması ve bu çalışmalara ait nicel bulguların birleştirilerek yorumlanması şeklinde tanımlanmaktadır (Dinçer, 2014, s. 4).

İlgili alanyazında öğrenci merkezli strateji, yöntem ve tekniklerin akademik başarı üzerindeki etkisinin, farklı dersler ve eğitim düzeyleri temel alınarak çalışıldığı belirlenmiştir. Araştırmada bu çalışma sonuçlarının belirli ölçütler dâhilinde birleştirilmesiyle, öğrenci merkezli strateji, yöntem ve tekniklerin akademik başarıya etkisinin bütüncül bir yapıda incelenmesi amaçlanmıştır. Bu nedenle çalışmada meta-analiz yöntemi tercih edilmiştir.

\section{Verilerin toplanması}

Araştırma kapsamına alınan yayınları; 2007-2016 yılları arasında TR Dizin, ERIC ve Social Sciences Citation Index veri tabanlarında taranan dergilerde yayımlanmış ve öğrenci merkezli strateji yöntem ve tekniklerin akademik başarı üzerindeki etkisini konu alan makaleler oluşturmuştur. Araştırmalarda kullanılan öğrenci merkezli strateji yöntem ve tekniklere yönelik son 10 yıldaki eğilimi belirlemek amacıyla tarama işlemi belirtilen zaman dilimiyle sınırlandırılmıştır. Belirtilen veri tabanlarının tercih edilmesi ise iki temel nedene dayanmaktadır. Bu nedenlerinden ilki, araştırmada ulusal ve uluslararası yayınları analize dâhil ederek, karşılaştırmalı ve kapsamlı sonuçları ulaşılmasının amaçlanmış olmasıdır. Diğer bir neden, belirtilen veri tabanlarının eğitim bilimleri alanında yayımlanmış ulusal ve uluslararası makalelere erişimi en iyi şekilde sağlamasıdır. Belirtilen veri tabanları ilk olarak 25 Mayıs 2016 tarihinde taranmış, 15 Şubat 2017 tarihinde tekrar taranarak gerekli kontroller yapılmıştır.

\section{Dâhil edilme ölçütleri}

Yayınlara ulaşılabilmek için veri tabanlarında "öğretim yöntemleri, öğretim stratejileri, öğretim teknikleri ve akademik başarı" anahtar kavramları ve aynı kavramların İngilizce karşılıkları tırnak içinde ve tırnak içinde verilmeden yazılarak tarama yapılmıştır. Bu tarama sonucunda öğrenci merkezli strateji, yöntem ve tekniklerin, öğretmen merkezli strateji yöntem ve tekniklere göre akademik başarı üzerindeki etkisini belirlemeyi amaçlayan ve tam metnine ulaşılabilen 126 deneysel araştırmaya ulaşılmıştır. Araştırmada; ön test-son test gruplu, en az iki grubun karşılaştırıldığı, deneysel ya da yarı deneysel desende gerçekleştirildiği belirtilen tüm çalışmalar kapsama alınmıştır. Ancak ulaşılan çalışmalar arasından meta-analize dâhil edilme ölçütlerini karşılamayanlar elenmiştir. Bu doğrultuda standart sapma değerine yer verilmeyen, ön test puanları eşit olmayan ya da eşitlenemeyen 21 çalışma analiz dışı bırakılmıştır. Sonuç olarak 105 araştırma analize dâhil edilmiş ve bu araştırmalardan toplam 120 etki büyüklügü katsayısı hesaplanmıştır.

\section{Çalışmaların kodlanması}

Araştırma kapsamına alınan bu çalışmalar, yayın sınıflama formu kullanılarak kodlanmıştır. Sınıflama formunda; çalışmanın yazarına, yılına, çalışmaların gerçekleştirildiği sınıf düzeyine, başarının ölçüldüğü alanlara, çalışmalarda kullanılan öğrenci merkezli strateji yöntem ve tekniklere, deney ve kontrol gruplarının öntest- sontest puan ortalamalarına, standart sapma değerlerine ve örneklem büyüklüklerine yer verilmiştir. Araştırma kapsamına alınan 
yayınlarda, başarının ölçüldüğü alanlara ve çalışmaların gerçekleştirildiği sınıf düzeyine ilişkin bilgiler Tablo 1'de sunulmuştur.

Tablo 1.

Çalışmalara İlişkin Bilgiler

\begin{tabular}{|c|c|c|c|c|}
\hline Değişken & & $\mathrm{f}$ & & $f$ \\
\hline \multirow{10}{*}{ Başarının Ölçüldüğü Alanlar } & Fen Bilimleri & 39 & Eğitim Bilimleri & 3 \\
\hline & Sosyal Bilgiler & 11 & Mühendislik & 3 \\
\hline & Kimya & 10 & Psikoloji & 2 \\
\hline & Matematik & 10 & Demokrasi ve Vatandaşlik & 1 \\
\hline & Fizik & 9 & Arap Dili & 1 \\
\hline & Biyoloji & 7 & Bilgi Teknolojileri & 1 \\
\hline & Tarım & 7 & Fransizca & 1 \\
\hline & Türkçe & 5 & Görsel Sanatlar & 1 \\
\hline & İngilizce & 4 & İnsan Kaynakları Yönetimi & 1 \\
\hline & Coğrafya & 3 & $\begin{array}{l}\text { Mesleki Gelişim ve } \\
\text { Yeterlikler }\end{array}$ & 1 \\
\hline \multirow{4}{*}{$\begin{array}{l}\text { Çalışmaların } \\
\text { Gerçekleştirildiği Sınıf } \\
\text { Düzeyi }\end{array}$} & İlkokul & & & 21 \\
\hline & Ortaokul & & & 55 \\
\hline & Ortaöğretim (9-12) & & & 13 \\
\hline & Yükseköğretim & & & 31 \\
\hline
\end{tabular}

Tablo 1 incelendiğinde, çalışmalarda çoğunlukla fen bilimleri alanındaki akademik başarının ölçüldüğü belirlenmiştir. Bunu takip eden alanlar; sosyal bilgiler, kimya, matematik ve fiziktir. Çalışmaların daha çok ortaokul düzeyinde gerçekleştirildiği ve ortaöğretim düzeyinde gerçekleştirilen araştırmaların sayıca az olduğu görülmektedir.

\section{Verilerin analizi}

Verilerin analizinde "Comprehensive Meta Analysis (CMA)" yazılımı kullanılarak, Hedges g'ye göre etki büyüklüğü katsayıları hesaplanmış ve bazı betimsel istatistikler için istatistiksel bir yazılımdan yararlanılmıştır. Etki büyüklüğü katsayıları hesaplandıktan sonra, ilgili alanyazında önerildiği gibi (Dinçer, 2014) heterojenlik testi yapılmış ve genel etkinin hesaplanması için uygun olan model seçilmiştir. Heterojenlik testi sonuçlarına göre uygun modelin seçim aşamaları bulgular bölümünde açıklanmıştır. Hesaplanan etki büyüklüğü katsayılarının yorumlanmasında ise aşağı belirtilen sınıflamadan yararlanılmıştır (Thalheimer ve Cook, 2002).

- $\quad-0.15-0.15$ önemsiz düzeyde

- $\quad 0.15-0.40$ küçük düzeyde

- $0.40-0.75$ orta düzeyde

- $\quad 0.75-1.10$ geniş düzeyde

- $1.10-1.45$ çok geniş düzeyde

- 1.45 - mükemmel düzeyde

Güvenirlik çalışmaları kapsamında öncelikle yayın yanlılığından kaçınmak için alanyazında önerildiği gibi (Dinçer, 2014) çalışmaların dâhil edilme ölçütleri nesnel olarak belirlenmiş, ayrıntılı değerlendirmeye tabi tutulan çalışmaları seçmek için sadece ulusal ve uluslararası alanda yayımlanmış makaleler araştırma kapsamına alınmıştır. İlgili alanyazında önerilen diğer yöntemler doğrultusunda (Çarkungöz ve Ediz, 2009; Dinçer, 2014; Üstün ve Eryılmaz, 2014); huni grafiği incelenmiş ve meta-analizde hesaplanan etki büyüklüğü katsayısını geçersiz kılacak zıt yönlü değere sahip çalışma sayısı (fail-safe N) hesaplanmıştır. Rosenthal yöntemiyle hesaplanan bu sayı 7021 çıkmıştır. Bu değer, araştırma bulgularının 
geçersiz sayılabilmesi için ilgili alanyazında 7021 tane zıt bulgulara sahip çalışmanın olması gerektiğini göstermektedir. Araştırmada, 105 çalışmadan 120 etki büyüklüğü katsayısı hesaplandığı düşünüldüğünde, 7021 çalışmanın oldukça yüksek olduğu görülmektedir. Buna ek olarak incelenen huni grafiği Şekil 1'de gösterilmiştir.

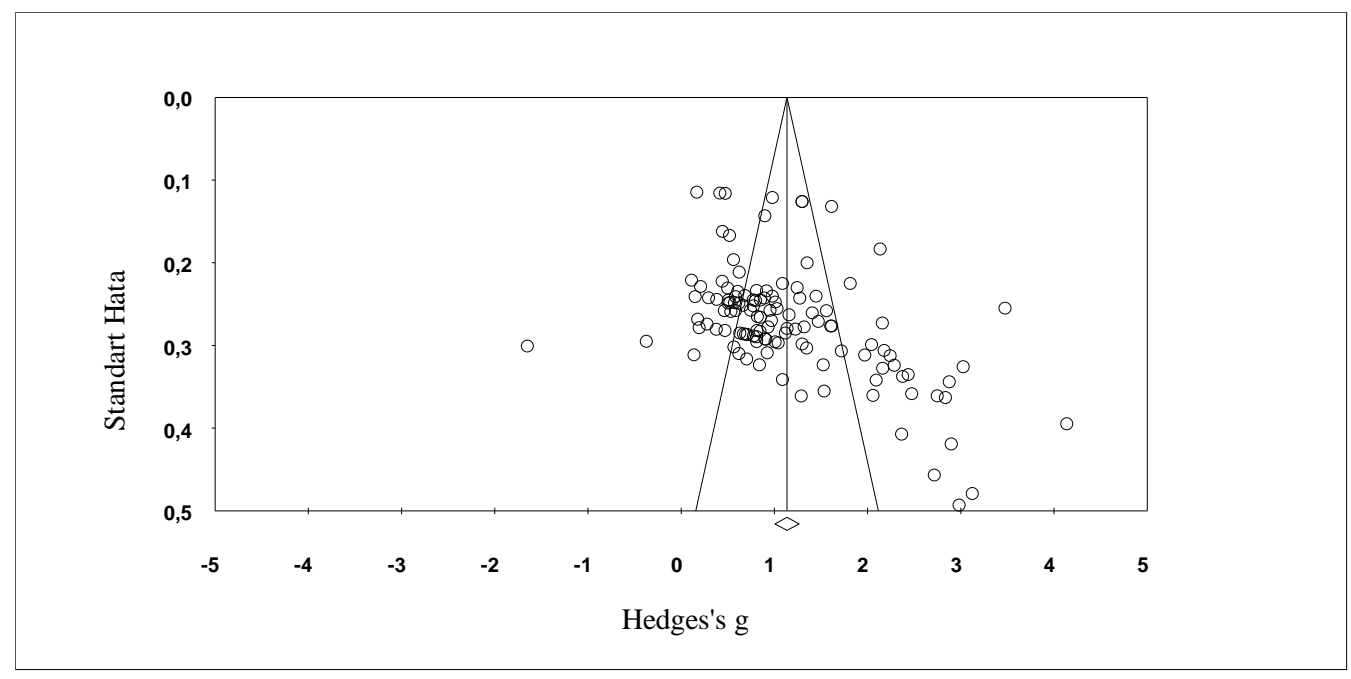

Şekil 1. Araştırmaya İlişkin Huni Grafiği

Şekil 1 incelendiğinde, çalışmaların etki büyüklüklerinin -1.64 ile 4.14 arasında olduğu görülmektedir. Şekil detaylı incelendiğinde çalışmaların bir bölümünün (f:51; f:20 sağ; f:31 sol); genel etki büyüklüğü olan 1.14'ün yayın yanlılığ1 sınır değerlerinden sapma yaptığ 1 belirlenmiştir. Ancak çalışmaların büyük bir çoğunluğunun (f:97) etki büyüklüğü katsayılarının .12 ile 1.97 aralığında değişmesi nedeniyle saçılmanın çok geniş bir alanda olmadı̆̆ görülmektedir. $\mathrm{Bu}$ durum bireysel çalışmaların fazla olduğu meta-analizlerde normal kabul edilmektedir (Dinçer, 2014).

\section{Bulgular}

Çalışmalarda kullanılan öğrenci merkezli strateji, yöntem ve teknikler

Araştırma kapsamına alınan yayınlarda kullanılan öğrenci merkezli strateji, yöntem ve teknikler Tablo 2'de belirtilmiştir.

Tablo 2.

Çalışmalarda Kullanılan Öğrenci Merkezli Strateji, Yöntem ve Teknikler

\begin{tabular}{|c|c|c|c|c|}
\hline \multicolumn{2}{|l|}{ Bağımsız Değişken } & $\mathrm{f}$ & Bağımsız Değişken & $\mathrm{f}$ \\
\hline \multirow{12}{*}{$\begin{array}{l}\text { Öğrenci Merkezli } \\
\text { Strateji, Yöntem } \\
\text { ve Teknikler }\end{array}$} & İşbirliğine Dayalı Öğrenme & 37 & Argümantasyon & 2 \\
\hline & Probleme Dayalı Öğrenme & 10 & Buluş Yoluyla Öğretim Stratejisi & 1 \\
\hline & Sorgulama Temelli Öğrenme & 9 & Beyin Temelli Öğrenme & 1 \\
\hline & Proje Tabanlı Öğrenme & 7 & Beyin Firtınas1 & 1 \\
\hline & Yaratıc1 Drama & 6 & Problem Çözme & 1 \\
\hline & 5E Öğrenme Modeli & 5 & İşbirliğine Dayalı Problem Çözme & 1 \\
\hline & Kavram Haritas 1 & 4 & Oyun Destekli Simülasyon & 1 \\
\hline & Örnek Olay & 4 & Kavram Haritas1-V Diyagramı & 1 \\
\hline & $\begin{array}{l}\text { Bilgisayar Destekli Eğitsel } \\
\text { Oyun }\end{array}$ & 4 & $\begin{array}{l}\text { Proje Tabanlıyla Desteklenen Çoklu } \\
\text { Zekâ }\end{array}$ & 1 \\
\hline & Yapılandırmacı Yaklaşım & 3 & Deney & 1 \\
\hline & Araştırmaya Dayalı Öğrenme & 3 & Kavram Ağı Yöntemi & \\
\hline & Dönüştürülmüş Sinıf & 3 & Zihin Haritas1 & 1 \\
\hline
\end{tabular}




\begin{tabular}{llll}
\hline Eğitsel Oyun & 2 & Yaparak Yazarak Bilim Öğrenimi & 1 \\
Altı Şapkalı Düşünme & 2 & Bütünsel Beyin Yaklaşımı & 1 \\
Tartışma Yöntemi & 2 & Durumlu Öğrenme & 1 \\
Aktif Öğrenme Yöntemi & 2 & & \\
\hline
\end{tabular}

Tablo 2 incelendiğinde, işbirliğine dayalı öğrenmenin en fazla kullanılan öğrenci merkezli yöntem olduğu görülmektedir. Bunun yanı sıra probleme dayalı öğrenme, sorgulama temelli öğrenme, proje tabanlı öğrenme, yaratıcı drama, 5E öğrenme modeli, kavram haritası, örnek olay, bilgisayar destekli eğitsel oyun, yapılandırmacı yaklaşım, araştırmaya dayalı öğrenme, dönüştürülmüş sınıf, eğitsel oyun ve argümantasyon gibi öğrenci merkezli strateji, yöntem ve tekniklerin birden fazla araştırmada kullanıldığı belirlenmiştir.

\section{Öğrenci merkezli strateji, yöntem ve tekniklerin akademik başarıya etkisi}

Öğrenci merkezli strateji, yöntem ve tekniklerin akademik başarıya etkisini belirlemek için gerekli etki büyüklüğü katsayılarının hesaplanmasında, deney ve kontrol gruplarının örneklem büyüklükleri, standart sapmaları ve son test puan ortalamaları kullanılmıştır. Bu kapsamda araştırmaya dâhil edilen çalışmaların birleştirilmemiş etki büyüklükleri ve genel etki büyüklüğü hesaplanmıştır. Çalışmaların birleştirilmemiş etki büyüklükleri, güven aralıkları ve çalışma ağırlıkları Tablo 3'te belirtilmiştir.

Tablo 3.

Çalışmaların Birleştirilmemiş Etki Büyüklükleri, Güven Aralığı ve Çalışmanın Ağırlığı

\begin{tabular}{|c|c|c|c|c|c|c|c|c|c|c|c|}
\hline \multirow{2}{*}{ 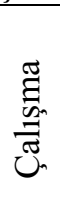 } & \multirow{2}{*}{ 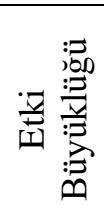 } & \multicolumn{2}{|c|}{ Güven Aralığ 1} & \multirow{2}{*}{$\begin{array}{c}\text { Çalışma } \\
\text { ağırlığ1 } \\
\text { (Sabit } \\
\text { Etkiler) }\end{array}$} & \multirow{2}{*}{$\begin{array}{c}\text { Çalışma } \\
\text { ağırlığ } 1 \\
\text { (Rastgele } \\
\text { Etkiler) }\end{array}$} & \multirow{2}{*}{ 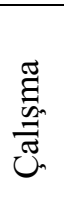 } & \multirow{2}{*}{ 竞总 } & \multicolumn{2}{|c|}{$\begin{array}{l}\text { Güven } \\
\text { Aralığ }\end{array}$} & \multirow{2}{*}{$\begin{array}{c}\text { Çalışma } \\
\text { a ăırlığı } \\
\text { (Sabit } \\
\text { Etkiler) }\end{array}$} & \multirow{2}{*}{$\begin{array}{l}\text { Çalışma } \\
\text { ağırlığ1 } \\
\text { (Rastgel } \\
\text { e Etkiler) }\end{array}$} \\
\hline & & 娄竞 & 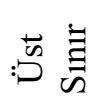 & & & & & 妾䒠 & : & & \\
\hline 1 & .58 & .09 & 1.07 & .78 & .86 & 39 & .75 & .24 & 1.25 & .73 & .85 \\
\hline 2 & 2.44 & 1.78 & 3.10 & .43 & .78 & 40 & .91 & .34 & 1.49 & .56 & .82 \\
\hline 3 & 2.90 & 2.08 & 3.73 & .27 & .70 & 41 & .14 & -.47 & .75 & .50 & .80 \\
\hline 4 & 2.25 & 1.63 & 2.86 & .49 & .80 & 42 & .84 & .21 & 1.48 & .46 & .79 \\
\hline 5 & .57 & -.02 & 1.16 & .53 & .81 & 43 & .45 & .01 & .88 & .97 & .88 \\
\hline 6 & 2.17 & 1.52 & 2.81 & .45 & .79 & 44 & 1.97 & 1.36 & 2.59 & .50 & .80 \\
\hline 7 & .78 & .30 & 1.26 & .80 & .86 & 45 & .61 & .15 & 1.07 & .88 & .87 \\
\hline 8 & .50 & .05 & .96 & .91 & .87 & 46 & 4.14 & 3.37 & 4.92 & .31 & .72 \\
\hline 9 & 1.48 & .94 & 2.01 & .66 & .84 & 47 & 2.72 & 1.82 & 3.62 & .23 & .67 \\
\hline 10 & 2.88 & 2.21 & 3.56 & .41 & .77 & 48 & 1.82 & 1.38 & 2.26 & .95 & .88 \\
\hline 11 & 1.61 & 1.07 & 2.15 & .63 & .83 & 49 & 1.53 & .89 & 2.16 & .46 & .79 \\
\hline 12 & 1.03 & .53 & 1.54 & .74 & .85 & 50 & .39 & -.09 & .87 & .81 & .86 \\
\hline 13 & 1.57 & 1.06 & 2.07 & .72 & .85 & 51 & 3.48 & 2.98 & 3.98 & .74 & .85 \\
\hline 14 & .86 & .37 & 1.34 & .80 & .86 & 52 & 2.38 & 1.72 & 3.04 & .42 & .78 \\
\hline 15 & .51 & .03 & .99 & .80 & .86 & 53 & 2.48 & 1.77 & 3.18 & .38 & .76 \\
\hline 16 & .63 & .21 & 1.04 & 1.08 & .89 & 54 & 1.62 & 1.08 & 2.16 & .63 & .83 \\
\hline 17 & 2.14 & 1.78 & 2.50 & 1.43 & .91 & 55 & .90 & .33 & 1.48 & .57 & .82 \\
\hline 18 & 2.18 & 1.58 & 2.78 & .52 & .81 & 56 & 1.25 & .80 & 1.70 & .91 & .87 \\
\hline 19 & .47 & -.04 & .98 & .73 & .85 & 57 & 1.54 & .84 & 2.24 & .38 & .76 \\
\hline 20 & .21 & -.24 & .66 & .92 & .87 & 58 & 2.05 & 1.46 & 2.63 & .54 & .81 \\
\hline 21 & .85 & .30 & 1.41 & .60 & .83 & 59 & .54 & .03 & 1.05 & .72 & .85 \\
\hline
\end{tabular}




\begin{tabular}{|c|c|c|c|c|c|c|c|c|c|c|c|}
\hline \multirow{2}{*}{ 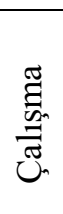 } & \multirow{2}{*}{ 吉 } & \multicolumn{2}{|c|}{ Güven Aralığ 1} & \multirow{2}{*}{$\begin{array}{c}\text { Çalışma } \\
\text { ağılığı } \\
\text { (Sabit } \\
\text { Etkiler) }\end{array}$} & \multirow{2}{*}{$\begin{array}{c}\text { Çalışma } \\
\text { ağılığı } \\
\text { (Rastgele } \\
\text { Etkiler) }\end{array}$} & \multirow{2}{*}{ 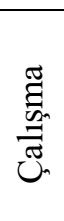 } & \multirow{2}{*}{ 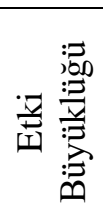 } & \multicolumn{2}{|c|}{$\begin{array}{l}\text { Güven } \\
\text { Aralığ }\end{array}$} & \multirow{2}{*}{$\begin{array}{l}\text { Çalışma } \\
\text { ağıılığı } \\
\text { (Sabit } \\
\text { Etkiler)e }\end{array}$} & \multirow{2}{*}{$\begin{array}{l}\text { Çalışma } \\
\text { ağılı̆̆ı } \\
\text { (Rastgel } \\
\text { e Etkiler) }\end{array}$} \\
\hline & & 击䚻 & 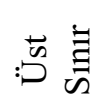 & & & & & 娄声 & $\stackrel{\vec{n}}{\text { 音 }}$ & & \\
\hline 22 & .38 & -.17 & .93 & .61 & .83 & 60 & .69 & .22 & 1.16 & .84 & .86 \\
\hline 23 & .12 & -.32 & .55 & .99 & .88 & 61 & 1.12 & .56 & 1.68 & .59 & .83 \\
\hline 24 & .53 & .04 & 1.02 & .78 & .86 & 62 & 3.13 & 2.19 & 4.07 & .21 & .65 \\
\hline 25 & 1.72 & 1.12 & 2.33 & .51 & .81 & 63 & .82 & .26 & 1.37 & .61 & .83 \\
\hline 26 & 2.99 & 2.02 & 3.95 & .20 & .63 & 64 & 1.23 & .68 & 1.78 & .61 & .83 \\
\hline 27 & .63 & .07 & 1.19 & .59 & .83 & 65 & 1.14 & .59 & 1.69 & .62 & .83 \\
\hline 28 & .52 & .20 & .85 & 1.73 & .92 & 66 & .86 & .33 & 1.38 & .68 & .84 \\
\hline 29 & .93 & .32 & 1.53 & .51 & .80 & 67 & .59 & .12 & 1.06 & .83 & .86 \\
\hline 30 & -1.64 & -2.24 & -1.05 & .53 & .81 & 68 & .78 & .29 & 1.28 & .76 & .85 \\
\hline 31 & .62 & .14 & 1.11 & .78 & .86 & 69 & .80 & .32 & 1.29 & .80 & .86 \\
\hline 32 & .17 & -.05 & .40 & 3.65 & .95 & 70 & .30 & -.18 & .78 & .82 & .86 \\
\hline 33 & .42 & .19 & .65 & 3.58 & .95 & 71 & .71 & .09 & 1.33 & .48 & .80 \\
\hline 34 & .48 & .25 & .71 & 3.56 & .95 & 72 & 3.03 & 2.39 & 3.67 & .45 & .79 \\
\hline 35 & .98 & .75 & 1.22 & 3.27 & .94 & 73 & 2.10 & 1.43 & 2.77 & .41 & .77 \\
\hline 36 & 1.30 & 1.05 & 1.55 & 3.03 & .94 & 74 & 1.09 & .65 & 1.53 & .95 & .88 \\
\hline 37 & 1.62 & 1.36 & 1.88 & 2.76 & .94 & 75 & 1.41 & .90 & 1.92 & .71 & .85 \\
\hline 38 & 1.30 & 1.05 & 1.55 & 3.03 & .94 & 76 & .96 & .45 & 1.46 & .73 & .85 \\
\hline 77 & 2.16 & 1.63 & 2.70 & .65 & .84 & 99 & .97 & .44 & 1.50 & .66 & .84 \\
\hline 78 & 1.35 & .76 & 1.95 & .53 & .81 & 100 & 2.06 & 1.36 & 2.77 & .37 & .76 \\
\hline 79 & .70 & .13 & 1.26 & .59 & .82 & 101 & .94 & .39 & 1.48 & .63 & .83 \\
\hline 80 & .62 & .02 & 1.23 & .50 & .80 & 102 & .82 & .30 & 1.34 & .69 & .84 \\
\hline 81 & -.37 & -.95 & .21 & .55 & .82 & 103 & 2.29 & 1.66 & 2.93 & .46 & .79 \\
\hline 82 & .82 & .25 & 1.38 & .58 & .82 & 104 & .59 & .08 & 1.10 & .73 & .85 \\
\hline 83 & .71 & .15 & 1.28 & .59 & .82 & 105 & 1.28 & .80 & 1.75 & .82 & .86 \\
\hline 84 & 1.01 & .43 & 1.59 & .55 & .82 & 106 & 2.84 & 2.13 & 3.55 & .37 & .75 \\
\hline 85 & .48 & -.08 & 1.03 & .61 & .83 & 107 & 1.09 & .42 & 1.76 & .41 & .77 \\
\hline 86 & .20 & -.35 & .74 & .62 & .83 & 108 & 1.29 & .59 & 2.00 & .37 & .76 \\
\hline 87 & .78 & .21 & 1.35 & .58 & .82 & 109 & .92 & .46 & 1.38 & .88 & .87 \\
\hline 88 & .90 & .42 & 1.37 & .82 & .86 & 110 & 1.05 & .46 & 1.63 & .55 & .82 \\
\hline 89 & 1.16 & .65 & 1.68 & .70 & .84 & 111 & .90 & .62 & 1.19 & 2.34 & .93 \\
\hline 90 & 1.30 & .72 & 1.89 & .54 & .81 & 112 & 1.01 & .53 & 1.50 & .79 & .86 \\
\hline 91 & .98 & .51 & 1.45 & .83 & .86 & 113 & .67 & .17 & 1.16 & .76 & .85 \\
\hline 92 & .51 & .02 & 1.00 & .78 & .86 & 114 & .82 & .24 & 1.39 & .55 & .82 \\
\hline 93 & 1.45 & .98 & 1.92 & .83 & .86 & 115 & .16 & -.32 & .63 & .83 & .86 \\
\hline 94 & 1.33 & .78 & 1.87 & .63 & .83 & 116 & 2.37 & 1.57 & 3.17 & .29 & .71 \\
\hline 95 & .18 & -.34 & .71 & .67 & .84 & 117 & .67 & .11 & 1.24 & .59 & .82 \\
\hline 96 & .57 & .18 & .95 & 1.25 & .90 & 118 & .45 & .13 & .77 & 1.83 & .92 \\
\hline 97 & .81 & .35 & 1.27 & .88 & .87 & 119 & 2.75 & 2.04 & 3.46 & .37 & .76 \\
\hline 98 & .28 & -.26 & .82 & .64 & .84 & 120 & 1.36 & .96 & 1.75 & 1.20 & .89 \\
\hline
\end{tabular}


Tablo 3'te yer alan etki büyüklüğü katsayıları incelendiğinde; iki çalışma haricinde, etki büyüklüğü katsayılarının pozitif olduğu görülmektedir. Etki büyüklüğü katsayıları negatif olan bu çalışmaların ortaokul düzeyinde gerçekleştirildiği, çalışmalarda işbirliğine dayalı öğrenme ve yaratıcı drama yöntemlerinin Türkçe ve matematik başarısı üzerindeki etkisinin incelendiği belirlenmiştir. Bununla birlikte etki büyüklüğü katsayısının .12 ile en düşük ve 4.14 ile en yüksek değere sahip olduğu her iki çalışmada, işbirliğine dayalı öğrenme yönteminin yükseköğretim düzeyinde çalışıldığı ve bu yöntemin Türk dili ve matematik başarısı üzerindeki etkisinin araştırıldığı tespit edilmiştir.

Etki katsayıları bütüncül bir şekilde değerlendirildiğinde, öğrenci merkezli strateji yöntem ve tekniklerin akademik başarı üzerinde etkili olduğu görülmektedir. Etki düzeylerinin sınıflandırılmasında ise alanyazında önerilen eşik değerler (Thalheimer ve Cook, 2002) dikkate alınmış ve ulaşılan bulgular Tablo 4 'te sunulmuştur.

Tablo 4.

Etki Büyüklüklerinin Sınıflandırılması

\begin{tabular}{ll}
\hline Etki büyüklügü düzeyi & $\mathrm{f}$ \\
\hline$-0,15-0,15$ önemsiz düzey & 2 \\
$0,15-0,40$ küçük düzey & 9 \\
$0,40-0,75$ orta düzey & 29 \\
$0,75-1,10$ geniş düzey & 30 \\
$1,10-1,45$ çok geniş düzey & 14 \\
1,45 ve üzeri mükemmel düzey & 34 \\
\hline
\end{tabular}

Tablo 4'te görüldüğü üzere 34 çalışmanın mükemmel, 30 çalışmanın geniş ve 29 çalışmanın ise orta düzeyde etki büyüklügüne sahip olduğu belirlenmiştir. Çalışmalardan 14 tanesi çok geniş, 9 tanesi küçük düzeyde etki büyüklüğüne sahipken, iki çalışmanın önemsiz düzeyde etki büyüklüğüne sahip olduğu görülmektedir. Araştırma kapsamına alınan çalışmalarda öğrenci merkezli strateji, yöntem ve tekniklerin akademik başarı üzerindeki genel etkisine ilişkin sonuçlar, sabit ve rastgele etkiler modelleri açısından karşılaştırılarak Tablo 5 'te gösterilmiştir.

Tablo 5.

Etki Modellerine Göre Meta-Analiz Sonuçlarının Karşılaştırılması

\begin{tabular}{|c|c|c|c|c|c|c|c|c|}
\hline \multirow[t]{2}{*}{ Model } & \multirow[t]{2}{*}{$\mathrm{N}$} & \multirow[t]{2}{*}{$\mathrm{Z}$} & \multirow[t]{2}{*}{$\mathrm{p}$} & \multirow[t]{2}{*}{ Q } & \multirow{2}{*}{$\begin{array}{c}\mathbf{X}^{2} \text { Tablo } \\
\text { Değeri } \\
(\mathrm{p}=.05)\end{array}$} & \multirow{2}{*}{$\begin{array}{c}\text { Etki } \\
\text { Büyüklüğü }\end{array}$} & \multicolumn{2}{|c|}{ Güven Aralığ1 } \\
\hline & & & & & & & 妾䒠 & 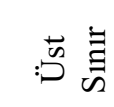 \\
\hline Sabit etkiler modeli & 120 & 45.07 & .00 & 1039.166 & 146.56 & .99 & .949 & 1.035 \\
\hline $\begin{array}{l}\text { Rastgele } \\
\text { modeli }\end{array}$ & 120 & 17.11 & .00 & 1039.166 & 146.56 & 1.14 & 1.006 & 1.266 \\
\hline
\end{tabular}

Tablo 5 incelendiğinde, sabit etkiler modeline göre \% 95'lik güven aralığında alt sınırın .949 , üst sınırın 1.035, genel etki büyüklüğ̈ katsayısının ise .99 değerinde olduğu görülmektedir. İstatistiksel anlamlllı amaciyla yapılan z testi sonucunda, z puanı $45.07 \mathrm{p}=$ $.00<.05$ olarak hesaplanmış ve sonucun istatistiksel açıdan anlamlı olduğu belirlenmiştir. Genel etkinin hesaplanması için kullanılacak modelin seçiminde heterojenlik testi yapılmıştır. $\mathrm{Bu}$ testin sonucunda Q-değeri 1039.166 olarak, p-değeri .00 olarak bulunmuştur. 119 serbestlik derecesi (df) ve \%95 anlamlılık düzeyi için $\chi^{2}$ tablosundaki Q-değeri 146.56 olduğu için çalışmaların heterojen yapıda olduğu sonucuna ulaşılmıştır. Bu nedenle analiz modeli olarak rastgele etkiler modeli kullanılmış, genel etki büyüklüğü 1.006 ile 1.266 sınırları içinde 1.14 olarak hesaplanmıştır. Bu değer, Thalheimer ve Cook'a göre (2002) çok geniş düzeyde etki 
olarak kabul edilmektedir. Bu kapsamda öğrenci merkezli strateji, yöntem ve tekniklerin akademik başarı üzerinde çok geniş düzeyde etkiye sahip olduğu belirlenmiştir.

\section{Etki büyüklüğü düzeylerinin farklılaşmasına neden olan etmenler}

Araştırma kapsamına alınan çalışmalar arasında, orta, geniş, çok geniş ve mükemmel düzeyde etki büyüklügüne sahip çalışmalar belirlenmiş ve akademik başarının ölçüldüğü alanlar açısından sınıflandırılmıştır. Bu sınıflamaya temel oluşturan alanlar; "fen, teknoloji, mühendislik ve matematik" ile "sosyal bilimler" olarak belirlenmiştir. Sonraki aşamada farklı alanlarda gerçekleştirilen bu çalışmalar, etki büyüklüğü düzeyleri açısından yorumlanmıştır. Başarının ölçüldüğü alanlara göre etki büyüklüğü düzeylerinin dağılımı Şekil 2'de gösterilmiştir.

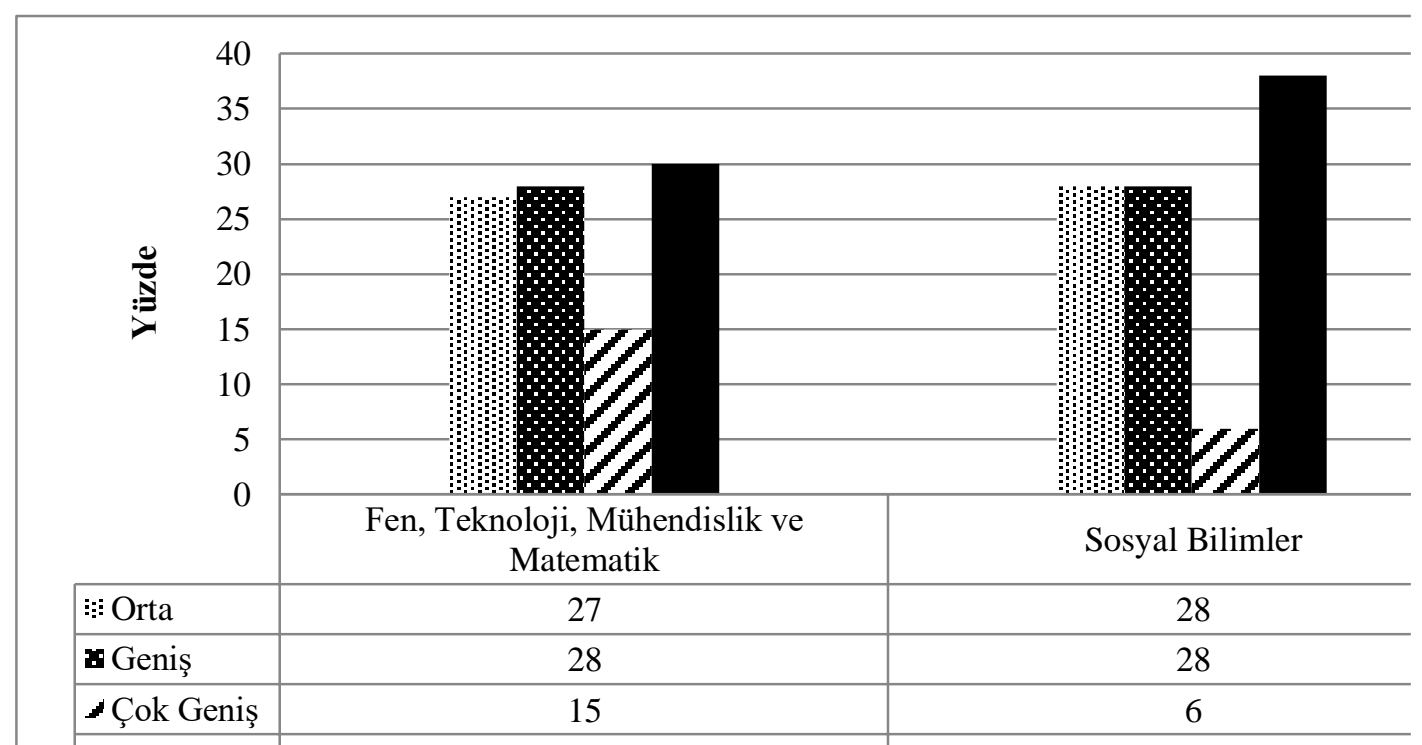

Şekil 2. Başarının Ölçüldüğü Alanlara Göre Etki Büyüklüğü Düzeyleri

Şekil 2 incelendiğinde, fen, teknoloji, mühendislik ve matematik alanında gerçekleştirilen çalışmaların \%30'unda ve sosyal bilimler alanında gerçekleştirilen çalışmaların \%38'inde mükemmel düzeyde etki büyüklügüne ulaşıldığı görülmektedir. Benzer şekilde, her iki alanda orta, geniş ve çok geniş düzeyde etki büyüklügüne sahip çalışma yüzdelerinin birbirine yakın olduğu belirlenmiştir. Çalışmaların gerçekleştirildiği sınıf düzeylerine göre etki büyüklügü düzeylerinin dağılımı Şekil 3 ’te gösterilmiştir. 


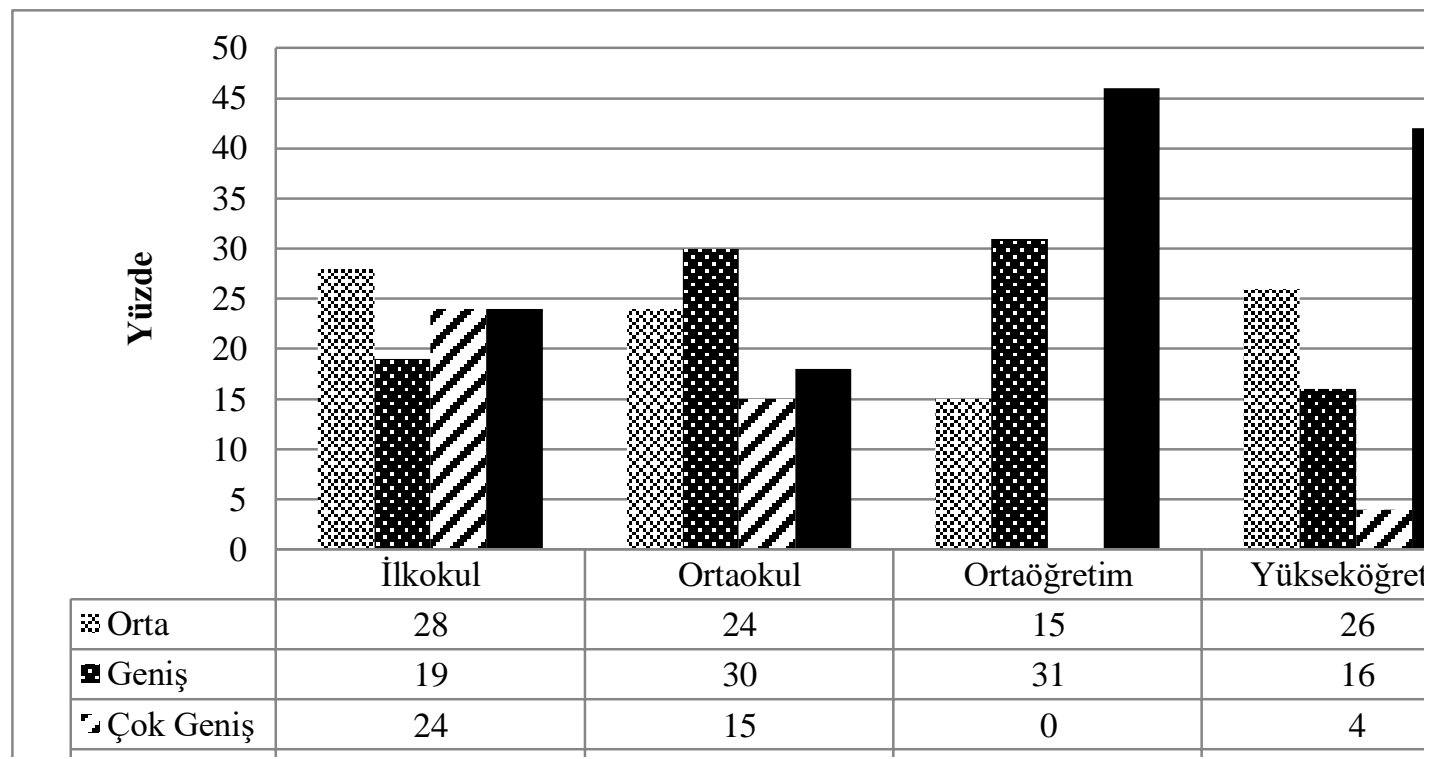

Şekil 3. Çalışmaların Gerçekleştirildiği Sınıf Düzeylerine Göre Göre Etki Büyüklüğü Düzeyleri

Şekil 3 incelendiğinde, ortaöğretim ve yükseköğretim düzeyinde gerçekleştirilen çalışmaların genellikle daha yüksek düzeyde etkiye sahip olduğu görülmektedir. Bu kapsamda yükseköğretim düzeyinde gerçekleştirilmiş çalışmaların \%42'sinin, ortaöğretim düzeyinde gerçekleştirilmiş çalışmaların ise \%46'sının mükemmel etkiye sahip olduğu belirlenmiş̧tir.

\section{Tartışma, Sonuç ve Öneriler}

Analiz sonuçları bütüncül bir şekilde değerlendirildiğinde, akademik başarıyı artırmak için sıklıkla kullanılan yöntemin işbirliğine dayalı öğrenme yöntemi olduğu ve öğrenci merkezli strateji, yöntem ve tekniklerin akademik başarı üzerinde daha çok orta, geniş ve mükemmel düzeyde etkiye sahip olduğu belirlenmiştir. Genel etki büyüklüğü incelendiğinde ise öğrenci merkezli strateji, yöntem ve tekniklerin öğretmen merkezli yaklaşımlara göre akademik başarı üzerinde çok geniş düzeyde etkiye sahip olduğu tespit edilmiştir. Ulaşılan bu bulgular farklı derslerde kullanılan öğrenci merkezli strateji yöntem ve tekniklerin öğrencilerin akademik başarısını artırdığını göstermektedir.

Benzer araştırmalarda da en fazla çalışılan yöntemler arasında işbirliğine dayalı öğrenme yönteminin olduğu görülmekte (Çelik, 2013; Yaşar ve diğerleri, 2015), öğrenci merkezli uygulamaların; akademik başarı üzerinde geniş (Çelik, 2013; Marzano ve diğerleri, 2001; Topan, 2013; Semerci ve Batdi, 2015; Ural ve Bümen, 2016) ve çok geniş (Ayaz ve Şekerci, 2015; Yaşar ve diğerleri, 2015) düzeyde etkiye sahip olduğunun belirlenmesi ulaşılan bulguları desteklemektedir. Araştırma bulgularını destekleyen diğer sonuçların öğrenci merkezli strateji, yöntem ve tekniklerin bireysel etkisine yönelik gerçekleştirilen meta-analiz çalışmalarından elde edildiği görülmektedir. $\mathrm{Bu}$ araştırmalarda; işbirliğine dayalı öğrenme (Biçer, 2017; Capar ve Tarım, 2015; Hattie, 2009; Jonhnson, Johnson ve Stanne, 2000; Kyndt ve diğerleri, 2013; Savelsbergh ve diğerleri, 2016; Schroeder ve diğerleri, 2007; Springer ve diğerleri, 1999; Şen ve Y1lmaz, 2013; Tarım, 2003; Tuncer ve Dikmen, 2017), probleme dayalı öğrenme (Ayaz, 2015; Vernon ve Blake 1993; Zhou ve diğerleri, 2016) ve proje tabanl1 öğrenme (Ayaz ve Söylemez, 2015) gibi yöntemlerin, öğretmen merkezli yaklaşımlara göre akademik başarıyı artırmada daha etkili olduğu belirlenmiştir.

Meta-analiz çalışmalarında, sentezlenecek birincil çalışmaların sayısının artması hem istatistiksel gücün ve hassasiyetin artmasına sebep olmakta hem de sonuçlarda tutarsızlıklar varsa sebeplerini araştırma esnekliği kazandırmaktadır (Üstün ve Eryılmaz, 2014). Bu araştırmada da işbirliğine dayalı öğrenme yönteminin daha fazla çalışıldığı 105 araştırmadan, 120 etki büyüklüğü katsayısı hesaplanmıştır. Çalışmalardan elde edilen etki büyüklüğü 
düzeylerinin önemsiz düzeyden mükemmel düzeye kadar farklı boyutlarda sinıflandırıldığ 1 tespit edilmiştir. Ancak etki büyüklüğü katsayısının .12 ile en düşük ve 4.14 değeriyle en yüksek değere sahip olduğu her iki çalışmada da işbirliğine dayalı öğrenme yönteminin yükseköğretim düzeyinde çalışıldığı belirlenmiştir. Çalışmaların homojen bir dağılım göstermemesi nedeniyle rastgele etkiler modeline göre genel etki büyüklüğü hesaplanmıştır. Bu nedenle benzer araştırmalardan elde edilen farklı sonuçların, incelenerek tartışılması amaçlanmıştır.

Sentezlenen bireysel çalışmalarda ulaşılan bu farklı sonuçlar, araştırmalarda kullanılan ölçme araçlarının standart olmayan yapısından kaynaklamış olabilir. Çünkü meta analiz çalışmalarında başarıyı ölçmede kullanılan araçların yapısının, etki düzeylerini yorumlamada dikkate alınması gereken önemli bir etmen olduğu belirtilmektedir (Dinçer, 2014; Jonhnson ve diğerleri, 2000). Bununla birlikte iki araştırmada etki büyüklüğünün negatif değere sahip olmas1 dikkati çekmektedir. Bu durum, öğretmen merkezli yaklaşımların, yaratıcı drama ve işbirliğine dayalı öğrenme yöntemlerine göre matematik ve Türkçe başarısı üzerinde daha etkili olduğunu göstermektedir. Araştırmacılar bu durumun nedenlerini; öğrencilerin kullanılan yöntemle daha önce karşılaşmamış olmalarıyla, matematiği günlük yaşamla ilişkilendirmede zorlanmalarıyla ve sosyal beceri düzeylerinin yetersiz olmasıyla ilişkilendirilmiş̧erdir.

Hattie'nin (2009) araştırmasında, öğrenci merkezli yöntemlerin, yüzeysel ve derinlemesine bilgi kazanımı üzerindeki farklı etkilere sahip olduğuna dikkat çekilmektedir. Yüzeysel bilgi kazanımını hedefleyen araştırmalarda probleme dayalı öğrenmenin negatif etkileri olduğu belirlenmiştir. Buna karşın derinlemesine öğrenme sürecinde öğrencilerin öncesinde yüzeysel bilgilere sahip olmaları nedeniyle bu yaklaşımın öğrenme üzerinde pozitif etkilerinin olabileceği ifade edilmektedir. Bu durumun nedenleri arasında, öğrenci merkezli yaklaşımlar arasında olan probleme dayalı öğrenmede, yüzeysel bilgi kazanımından ziyade anlamaya ağırlık verilmesi gösterilmektedir.

İlgili araştırmaların sonuçları, öğrenci merkezli yöntem ve tekniklerin etkili kullanımı için beceri düzeyinde kazanımların hedeflenmesi gerektiğini göstermektedir (Brown, 2003; Cornelius-White, 2007; Dochy, Segers, Van den Bossche ve Gijbels, 2003; Hattie, 2009; Marzano ve diğerleri, 2001). Beceri düzeyinde kazanımlara ulaşılması için, öğrencilerin öncelikle temel bilgileri anlamlandırmaları ve duyuşsal açıdan hazırlanmaları gerekmektedir. Negatif etki büyüklüğüne sahip araştırmalarda da belirtildiği üzere öğrenci merkezli yöntemlerin kullanımında; çalışılan konunun yapısının, öğrencilerin konuya ilişkin kazandıkları temel bilgilerin, değer ve tutumların dikkate alınması gerekmekte ve ön testler haricinde kontrol altına alınması gereken farklı değişkenlerin olduğu görülmektedir. Araştırmada elde edilen diğer bulguların da bu durumu desteklediği belirlenmiştir. $\mathrm{Bu}$ kapsamda ortaöğretim ve yükseköğretim düzeyinde gerçekleştirilen çalışmaların genellikle daha yüksek düzeyde etkiye sahip olduğu görülmektedir. Benzer meta-analiz çalışmalarında da işbirliğine dayalı öğrenme (Capar ve Tarım, 2015; Özdemirli, 2011; Tarım, 2003), proje tabanlı öğrenme (Ayaz ve Söylemez, 2015) ve beyin temelli öğrenme (Gözüyeşil, 2012) gibi öğrenci merkezli yöntemlerin ortaöğretim ve yükseköğretim öğrencilerinin akademik başarısı üzerinde daha etkili olduğu belirlenmiştir. Bu durum öğrencilerin yaşına bağlı olarak konuya ilişkin ön bilgi, beceri ve tutum düzeylerinin öğrenci merkezli strateji, yöntem ve tekniklerin kullanımında dikkate alınması gereken önemli bir değişken olduğunu göstermekte ve öğrenci merkezli yöntemlerin kullanımında; çalışılan öğrencilerin konuya ilişkin kazandıkları temel bilgilerin dikkate alınması gerektiği görüşünü desteklemektedir.

Sonuç olarak araştırmada, öğrenci merkezli strateji yöntem ve tekniklerin öğretmen merkezli yaklaşımlara göre farklı derslerdeki akademik başarının artııılmasıyla daha ilişkili olduğu ve bu strateji, yöntem ve tekniklerin akademik başarıyı artırmada çok geniş düzeyde bir etkiye sahip olduğu belirlenmiştir. Bununla birlikte çalışılan konunun yapısının, ölçme aracının özelliklerinin ve kontrol altına alınması gereken öğrenci kaynaklı değişkenlerin, etki büyüklügü̈ düzeylerini farklılaştırdığı ortaya konmuştur.

Ulaşılan bu sonuçlar, farklı derslerin öğretiminde kullanılan öğrenci merkezli yaklaşımların, akademik başarıyı artırmada önemli bir değişken olduğunu göstermektedir. 
Ancak amaçlara uygun bir öğretim sürecinin gerçekleştirilmesi ve değerlendirilmesi için, strateji yöntem ve tekniğin seçiminden önce; içeriğin, ölçme aracının ve öğrenci özelliklerinin gözden geçirilmesi önerilmektedir.

\section{Sinırlılıklar}

Bu meta-analiz çalışmadan elde edilen sonuçlar, 2007-2016 yılları arasında TR Dizin, ERIC ve Social Sciences Citation Index veri tabanlarında taranan dergilerde yayımlanmış ve öğrenci merkezli strateji yöntem ve tekniklerin akademik başarı üzerindeki etkisini konu alan makalelerle sınırlıdır. Ulusal ve uluslararası veri tabanlarında yer alan lisanüstü tezler inceleme kapsamına alınmamıştır. Bu nedenle ileride gerçekleştirilecek meta-analiz araştırmalarında; bu sinırlılıklar göz önünde bulundurularak ulusal ve uluslararası tezler ve farklı veritabanlarında yayımlanan makaleler çalışmaya dahil edilerek öğrenci merkezli strateji yöntem ve tekniklerin akademik başarı üzerindeki etkisi daha kapsamlı bir yapıda incelenebilir ve bu çalışmaların karşılaştırılmasına yönelik araştırmalar gerçekleştirilebilir.

\section{Kaynaklar}

Araştırma kapsamında analiz edilen yayınlar * işaretiyle belirtilerek kaynakçaya eklenmiştir.

*Abdi, A. (2014). The effect of inquiry-based learning method on students' academic achievement in science course. Universal journal of educational Research, 2(1), 37-41. doi:10.13189/ujer.2014.020104.

*Akay, S. Ö., Kaya, B. ve Kılıç, S. (2012). The effects of concept maps on the academic success and attitudes of 11th graders while teaching urinary system. International Journal of New Trends in Arts, Sports \& Science Education, 1(3), 55-62.

*Akengin, H. ve Aydemir, G. (2012). Effects of using case-study method in social studies on students' attitudes towards environment. International Electronic Journal of Environmental Education, 2(2), 119-127.

*Akınoğlu, O. ve Özkardeş-Tandoğan, R. (2007). The effects of problem-based active learning in science education on students' academic achievement, attitude and concept learning. Eurasia Journal of Mathematics, Science \& Technology Education, 3(1), 71-81.

*Akinsola, M. K. ve Animasahun, I. A. (2007). The effect of simulation-games environment on students' achievement in and attitudes to mathematics in secondary schools. TOJET: The Turkish Online Journal of Educational Technology, 6(3), 113-119.

*Aksoy, G. ve Doymuş, K. (2011). Fen ve teknoloji dersi uygulamalarında işbirlikli okumayazma-uygulama tekniğinin etkisi. Gazi Üniversitesi Gazi Ĕgitim Fakültesi Dergisi, 31(2), 381-397.

*Aktaş, M. (2013). 5E öğrenme modeli ve işbirlikli öğrenme yönteminin biyoloji dersi başarısına etkisi. Ahi Evran Üniversitesi Kırşsehir Eğitim Fakültesi Dergisi, 14(3), 3758.

*Aladağ, S. (2008). İlköğretim matematik öğretiminde proje tabanlı öğrenme yaklaşımının öğrencilerin akademik başarısına etkisi. Türkiye Sosyal Araştırmalar Dergisi, 12(2), 157-170.

*Alaz, A. (2009). Çoklu zekâ kuramı destekli eğitimin dokuzuncu sınıf coğrafya derslerinde başarıya etkisi. Türk Ë̆itim Bilimleri Dergisi, 7(1), 1-22.

*Alghamdi, A. (2013). Pedagogical implications of using discussion board to improve student learning in higher education. Higher Education Studies, 3(5), 68-80.

*Arıbaş, S. ve Fırat, Ş. (2010). İlköğretim 4. sınıf öğrencilerinin Sosyal Bilgiler dersine yönelik akademik başarıları üzerinde proje tabanlı öğrenme yaklaşımının etkisi. Milli Eğitim Dergisi, 186, 310-319.

*Arslan, A. (2012). Sözcük türleri öğretiminde Jigsaw tekniğinin etkisi. Dumlupınar Üniversitesi Sosyal Bilimler Dergisi, 1(32), 157-168.

*Asha, I. K. ve Al Hawi, A. M. (2016). The impact of cooperative learning on developing the sixth-grade students decision-making skill and academic achievement. Journal of Education and Practice, 7(10), 60-70. 
*Aydede, M. N. ve Matyar, F. (2009). Aktif öğrenme yaklaşımının fen bilgisi dersindeki akademik başarı ve kalıc1lığa etkisi. Kastamonu Ĕ̌itim Dergisi, 17(1), 137-152.

*Balım, A. G. (2009). The effects of discovery learning on students' success and inquiry learning skills. Eurasian Journal of Educational Research, 35, 1-20.

*Baş, G. ve Beyhan, Ö. (2017). Effects of multiple intelligences supported project-based learning on students' achievement levels and attitudes towards English lesson. International Electronic Journal of Elementary Education, 2(3), 365-386.

*Bayram, H. ve Seloni, Ş. R. (2014). Proje tabanlı öğrenme yaklaşımının ilköğretim 5. sınıf öğrencilerinin fen bilgisi başarılarına, kavramsal anlamalarına ve tutumlarına etkisi. Ĕgitim Bilimleri Dergisi, 39, 71-84. doi: 10.15285/EBD.2014397398.

*Bekmezci, B. ve Ünlü, M. (2007). Coğrafya öğretiminde grupla çalışma metodunun öğrenci başarısına etkisi. Marmara Coğrafya Dergisi, 16, 53-64.

*Benli, E. ve Sarikaya, M. (2012). The investigation of the effect of problem based learning to the academic achievement and the permanence of knowledge of prospective science teacher: The problem of the boiler stone. Procedia-Social and Behavioral Sciences, 46, 4317-4322. doi: 10.1016/j.sbspro.2012.06.247.

*Bıyıklı, C. ve Yağc1, E. (2015). 5E öğrenme modeline göre düzenlenmiş eğitim durumlarının akademik başarı ve tutuma etkisi. Abant İzzet Baysal Üniversitesi Eğitim Fakültesi Dergisi, 15(1), 302-325.

*Bozkurt, O. (2012). Fen eğitiminde araştırmaya dayalı öğrenme yaklaşımının öğrencilerin akademik başarılarına ve bilimsel süreç becerilerine etkisi. Mustafa Kemal Üniversitesi Sosyal Bilimler Enstitüsü Dergisi, 9(18). 187-200.

*Bozkurt, O., Ay, Y. ve Fansa, M. (2013). Araştırmaya dayalı öğrenmenin fen başarısı ve fene yönelik tutuma etkisi ile öğretim sürecine yönelik öğrenci görüşleri. Abant İzzet Baysal Üniversitesi Ĕ̈itim Fakültesi Dergisi, 13(2), 241-256.

*Bozkurt, O., Orhan, T. A., Keskin, A. ve Mazi, A. (2008). Fen ve teknoloji dersinde işbirlikli öğrenme yönteminin akademik başarıya etkisi. Türkiye Sosyal Araştırmalar Dergisi, 2, 63-78.

*Çakmak, M., Gürbüz, H. ve Kaplan, H. (2012). Dolaşım sistemimiz konusunda uygulanan kavram haritalarının öğrencilerin akademik başarısına etkisi. Adlyaman Üniversitesi Sosyal Bilimler Enstitüsü Dergisi, 5(10), 9-28.

*Çalışkan, H. ve Turan, R. (2008). Araştırmaya dayalı öğrenme yaklaşımının sosyal bilgiler dersinde akademik başarıya ve kalıcılık düzeyine etkisi. Türk Ĕgitim Bilimleri Dergisi, 6(4), 603-627.

*Can, H. A. ve Semerci, N. (2007). The effect of "the six thinking hats technique" on the students' academic achievement in social studies at primary school. Education \& Science, 32(145), 39.

*Candaş-Karababa, Z. C. (2009). Effects of cooperative learning on prospective teachers' achievement and social interactions. Hacettepe University Journal of Education, 36, 3240.

*Çelik, E., Eroğlu, B. ve Selvi, M. (2012). Fen eğitiminde probleme dayalı öğrenme yaklaşımının öğrencilerin akademik başarısı ile fen ve teknoloji dersine yönelik tutumlarına etkisi. Kastamonu Ĕgitim Dergisi, 20(1), 187-202.

*Çeliker, H. D. ve Balım, A. G. (2012). Güneş sistemi ve ötesi: uzay bilmecesi ünitesinde proje tabanlı öğrenme uygulamalarının öğrenci başarılarına etkisi. Kuramsal Eğitimbilim Dergisi, 5(3), 254-277.

*Çepni, S. ve Çoruhlu, T. Ş. (2014). Güneş sistemi ve ötesi: Uzay bilmecesi ünitesinde zenginleştirilmiş 5e öğretim modeline uygun hazırlanan öğrenme ortamlarının öğrenci başarısı üzerine etkisinin incelenmesi. Uludă̆ Üniversitesi Eğitim Fakültesi Dergisi, 27(2), 343-369.

*Chen, S. C. (2010). Instructional experiment of practical competencies-oriented teaching materials in technical universities. American Journal of Business Education, 3(9), 51. 
*Chung-Ho, S. U. ve Ching-Hsue, C. (2013). 3D game-based learning system for improving learning achievement in software engineering curriculum. TOJET: The Turkish Online Journal of Educational Technology, 12(2), 1-12.

*Çinici, A., Özden, M., Akgün, A., Herdem, K., Karabiber, H. L. ve Deniz, Ş. M. (2014). Kavram karikatürleriyle desteklenmiş argümantasyon temelli uygulamaların etkinliğinin incelenmesi. Adlyaman Üniversitesi Sosyal Bilimler Enstitüsü Dergisi, 7(18), 571-596. doi: 10.14520/adyusbd.839.

*Demir, M. (2012). Yaparak yazarak bilim öğrenimi- YYBÖ yaklaşımının ilköğretim öğrencilerinin fen akademik başarılarına ve fen ve teknoloji dersine yönelik tutumlarına etkisi. Milli Ĕgitim Dergisi, 195, 146-165.

*Demirbaş, M. ve Bozdoğan, A. E. (2008). Fizik laboratuvarı dersinde işbirlikli öğrenme yönteminin öğrencilerin akademik başarısını geliştirme etkisinin araştırılması. Ondokuz Mayls Üniversitesi Ë̆itim Fakültesi Dergisi, 26, 25-34.

*Demirci, C. (2010). Cooperative learning approach to teaching science. Eurasian Journal of Educational Research, 40, 36-52.

*Doğan, A., Uygur, E., Doymuş, K. ve Karaçöp, A. (2010). İlköğretim 7. Sınıf fen ve teknoloji dersinde jigsaw tekniğinin uygulanması ve bu teknik hakkındaki öğrenci görüşleri. Erzincan Eğitim Fakültesi Dergisi, 12(1), 75-90.

*Doymuş, K. ve Şimşek, Ü. (2007). Kimyasal bağların öğretilmesinde jigsaw tekniğinin etkisi ve bu teknik hakkında öğrenci görüşleri. Milli Eğitim Dergisi, 173, 231-244.

*Doymus, K. (2008). Teaching chemical equilibrium with the jigsaw technique. Research in Science Education, 38(2), 249-260. doi: 10.1007/s11165-007-9047-8

*Duman, B. (2010). Effects of brain-based learning on academic achievement: A sample case of in-class application. Eurasian Journal of Educational Research, 41, 91-115.

*Eren, C. D. ve Gürdal, A. (2010). Fizik dersinde parçalı öğretim tekniğinin kullanılmasının öğrencilerin başarısına, hatırlamasına ve grup çalışmasına yaklaşımlarına etkisi. Pamukkale Üniversitesi Ë̆itim Fakültesi Dergisi, 28, 67-79.

*Ergin, İ. (2009). 5e modelinin öğrencilerin akademik başarısına ve hatırlama düzeyine etkisi: Eğik atış hareketi örneği. Mehmet Akif Ersoy Üniversitesi Eğitim Fakültesi Dergisi, 9(18), 11-26.

*Ergül, N. R. ve Kargin, E. K. (2014). The effect of project based learning on students' science success. Procedia-Social and Behavioral Sciences, 136, 537-541. doi:10.1016/j.sbspro. 2014.05.371

*Gök, T. ve S1lay, İ. (2008). The effects of problem-solving strategies on students' achievement, on the cooperative learning groups in physics teaching. Hacettepe University Journal of Education, 34, 116-126.

*Gömleksiz, M. N. ve Yetkiner, A. (2012). İngilizce öğretiminde zihin haritası kullanımının öğrencilerin akademik başarıları, kalıcılık ile İngilizceye ilişkin görüş ve tutumlarına etkisi. Elektronik Sosyal Bilimler Dergisi, 11(40), 129-160.

*Gümüş, O. ve Buluç, B. (2007). İşbirliğine dayalı öğrenme yaklaşımının Türkçe dersinde akademik başarıya etkisi ve öğrencilerin derse ilgisi. Kuram ve Uygulamada Eğitim Yönetimi, 49, 7-30.

*Hossainy, F. N., Zare, H., Hormozi, M., Shaghaghi, F. ve Kaveh, M. H. (2012). Designing and 1mplementing a situated learning program and determining its impact on the students' motivation and learning. Turkish Online Journal of Distance Education, 13(2), 36-47.

*İbrahimoğlu, Z. ve Öztürk, C. (2013). Sosyal bilgiler dersinden örnek olay yöntemi kullanımının öğrencilerin akademik başarı derse karşı tutum ve eleştirel düşünme becerileri üzerine etkileri. Uludă̆ Üniversitesi Ĕ̈itim Fakültesi Dergisi, 26(2), 523547.

*İnce, E., Güven, E. ve Aydoğdu, M. (2010). Fen bilgisi laboratuar uygulamaları dersinde kavram haritası ve V diyagramının akademik başarı ve kalıcılığa etkisi. Çukurova Üniversitesi Sosyal Bilimler Enstitüsü Dergisi, 19(2), 378-394. 
*Işık, D. ve Tarım, K. (2009). The effects of the cooperative learning method supported by multiple intelligence theory on Turkish elementary students' mathematics achievement. Asia Pacific Education Review, 10(4), 465. doi: 10.1007/s12564-009-9049-5.

*Işık, D., Tarım, K. ve İflazoğlu, A. (2007). Çoklu zekâ kuramı destekli kubaşık öğrenme yönteminin ilköğretim 3. sınıf öğrencilerinin matematik dersindeki akademik başarılarına etkisi. Ahi Evran Üniversitesi Kırşehir Eğitim Fakültesi Dergisi, 8(1), 6377.

*Jui-Mei, Y., Chun-Ming, H., Hwang, G. J. ve Yueh-Chiao, L. I. N. (2011). A game-based learning approach to improving students' learning achievements in a nutrition course. TOJET: The Turkish Online Journal of Educational Technology, 10(2), 1-10.

*Kablan, Z. (2010). Öğretim sürecinde bilgisayara dayalı alıştırma amaçlı oyun kullanılmasının eğitim fakültesi öğrencilerinin akademik başarısına etkisi. Educational Sciences: Theory \& Practice, 10(1), 335-364.

*Kahyaoğlu, H., Yavuzer, Y. ve Aydede, M. N. (2010). Fen bilgisi dersinin öğretiminde yaratıc1 drama yönteminin akademik başarıya etkisi. Türk Eğitim Bilimleri Dergisi, 8(3), 741758.

*Kalyoncu, R. ve Tepecik, A. (2009). İlköğretim 8. sınıf görsel sanatlar dersi kent projesi konusunda proje tabanlı öğrenmeye dayalı bir uygulama örneği. Educational Sciences: Theory \& Practice, 10(4), 2375-2430.

*Kaplan, A., Öztürk, M. ve Ertör, E. (2013). The efficiency of computer-aided instruction and creative drama on academic achievement in teaching of integers to seventh grade students. International Journal of Academic Research Part B, 5(2), 49-56. doi: 10.7813/2075-4124.2013/5-2/B.7.

*Karacop, A. ve Doymus, K. (2013). Effects of jigsaw cooperative learning and animation techniques on students' understanding of chemical bonding and their conceptions of the particulate nature of matter. Journal of Science Education and Technology, 22(2), 186203. doi: 10.1007/s10956-012-9385-9

*Karakuş, F. (2012). Oluşturmacı öğrenme ve otantik değerlendirme yaklaşımlarının sosyal bilgiler öğretiminde öğrencilerin akademik başarı ve kalıcılığa etkisi. Çukurova Üniversitesi Sosyal Bilimler Enstitüsü Dergisi, 21(1), 101-116.

*Karakuş, U. ve Tonga, D. (2013). Sosyal bilgiler dersinde deney kullanımının akademik başarıya etkisi. Kastamonu Eğitim Dergisi, 21(2), 638-648.

*Kavacık, L., Yelken, T. Y. ve Sürmeli, H. (2015). İlköğretim Fen ve Teknoloji Dersinde İnovasyon (Yenilikçi) Proje Uygulamaları ve Öğrenciler Üzerindeki Etkileri. Education \& Science, 40(180), 247-263. doi:10.15390/EB.2015.2613.

*Kılıç, İ. ve Moralar, A. (2015). Fen eğitiminde probleme dayalı öğrenme yaklaşımının akademik başarı ve motivasyona etkisi. Pegem Eğitim ve Öğretim Dergisi, 5(5), 625636. doi:10.14527/pegegog.2015.034.

*Kılınçaslan, H. ve Şimşek, P. Ö. (2015). 6. Sinıf "Kuvvet ve Hareket" Ünitesinde Basamaklı Öğretim Yöntemi ve Yaratıcı Drama Yönteminin Erişiye, Tutuma ve Kalıcılığa Etkisi. Education \& Science, 40(180),217-245. doi:10.15390/EB.2015.4380.

*Kuş, Z. ve Karatekin, K. (2009). İş birliğine dayalı öğrenmenin sosyal bilgiler dersinde akademik başarı üzerine etkisi. Uludağ Üniversitesi Eğitim Fakültesi Dergisi, 22(2), 589-604.

*Leo, J. ve Puzio, K. (2016). Flipped instruction in a high school science classroom. Journal of Science Education and Technology, 25(5), 775-781. doi: 10.1007/s10956-016-9634-4.

*Maden, S. (2011). Jigsaw I tekniğinin yazılı anlatım becerisi akademik başarısına etkisi. Educational Sciences: Theory \& Practice, 11(2), 901-917.

*Onweh, V. E. ve Akpan, U. T. (2014). Instructional strategies and students' academic performance in electrical installation in technical colleges in Akwa Ibom State: Instructional skills for structuring appropriate learning experiences for students. International Journal of Educational Administration and Policy Studies, 6(5), 80-86. doi: 10.5897/IJEAPS2014.0347 
*Özbudak, Z. ve Özkan, M. (2014). İnsanda bazı kalıtsal özelliklerin 5E modeline dayal1 etkinliklerle öğretiminin akademik başarı, tutum ve kalıcılığa etkisi. Uludă̆ Üniversitesi Ĕ̈itim Fakültesi Dergisi, 27(1), 185-206.

*Özçelik, N. ve Aydeniz, H. (2012). Yaratıcı drama yönteminin üniversite öğrencilerinin akademik başarılarına ve Fransızca konuşmaya yönelik tutumlarına etkisi. Atatürk Üniversitesi Sosyal Bilimler Enstitüsü Dergisi, 16(2), 231-248.

*Özdemir, E. ve Arslan, A. (2016). The effect of self-regulated jigsaw IV on university students' academic achievements and attitudes towards English course. Journal of Education and Training Studies, 4(5), 173-182. doi: 10.11114/jets.v/jets.v/jets.v4i5. 1453.

*Özek, M. B. (2016). The effect of creative drama on student achievement in the course of information technologies. Journal of Education and Training Studies, 4(6), 51-57. doi:10.11114/jets.v4i6.1370.

*Özpinar, İ., Yenmez, A. A. ve Gökçe, S. (2016). An application of flipped classroom method in the instructional technologies and material development course. Journal of Education and Training Studies, 4(12), 213-226. doi:10.11114/ jets.v4i12.1934.

*Parveen, Q. ve Batool, S. (2012). Effect of cooperative learning on achievement of students in general science at secondary level. International Education Studies, 5(2), 154-158. doi:10.5539/ies.v5n2p154.

*Perveen, K. (2010). Effect of the problem-solving approach on academic achievement of students in mathematics at the secondary level. Contemporary Issues in Education Research, 3(3), 9-14.

*Podges, J. M., Kommers, P. K., Winnips, K. W. ve Van Joolingen, W. V. J. (2014). Mixing problem based learning and conventional teaching methods in an analog electronics course. American Journal of Engineering Education, 5(2), 99-114.

*Rizi, C. E., Najafipour, M. ve Dehghan, S. (2013). The effect of the using the brainstorming method on the academic achievement of students in grade five in Tehran elementary schools. Procedia-Social and Behavioral Sciences, 83, 230-233. doi:10.1016/j.sbspro. 2013.06.045.

*Şahin, A. (2011). Effects of Jigsaw III technique on achievement in written expression. Asia Pacific Education Review, 12(3), 427-435. doi:10.1007/s12564-010-9135-8.

*Sarı, U. ve Güven, G. B. (2013). Etkileşimli tahta destekli sorgulamaya dayalı fizik öğretiminin başarı ve motivasyona etkisi ve öğretmen adaylarının öğretime yönelik görüşleri. Necatibey Eğitim Fakültesi Elektronik Fen ve Matematik Ĕgitimi Dergisi, $7(2), 110-143$.

*Sarıca, R. ve Çetin, B. (2012). Öğretimde kavram haritaları kullanımının öğrencilerin akademik başarısına ve kalıcılığa etkisi. İlköğretim Online, 11(2), 306-318.

*Sarıkaya, M., Güven, E., Göksu, V. ve İnce-Aka, E. (2010). Yapılandırmacı yaklaşımın öğrencilerin akademik başarı ve bilgilerinin kalıc1lı̆̆ üzerine etkisi. İlköğretim Online, 9(1), 413-423.

*Şenol, H., Bal, Ş. ve Yıldırım, H. İ. (2007). İlköğretim 6 sınıf fen bilgisi dersinde duyu organları konusunun işlenmesinde işbirlikli öğrenme yönteminin öğrenci başarısı ve tutum üzerinde etkisi. Kastamonu Eğitim Dergisi, 15(1), 211-220.

*Sezgin-Selçuk, G., Karabey, B. ve Çalışkan, S. (2011). Probleme-dayalı öğrenmenin matematik öğretmen adaylarının ölçme ve vektörler konularındaki başarıları üzerindeki etkisi. Mustafa Kemal Üniversitesi Sosyal Bilimler Enstitüsü Dergisi, 8(15), 313-322.

*Sun, J. C. Y. ve Wu, Y. T. (2016). Analysis of learning achievement and teacher-student interactions in flipped and conventional classrooms. The International Review of Research in Open and Distributed Learning, 17(1), 79-99.

*Temelli, A. ve Kurt, M. (2011). Bitkilerde taşıma sistemi konusunun kavram haritalariyla öğretilmesinin öğrencilerin akademik başarısına etkisi (Erzurum örneği). Necatibey Ĕ̈itim Fakültesi Elektronik Fen ve Matematik Eğitimi Dergisi, 5(2), 42-57. 
*Thoron, A. C. ve Myers, B. E. (2011). Effects of inquiry-based agriscience instruction on student achievement. Journal of Agricultural Education, 52(4), 175-187. doi: 10.5032/jae.2011.04175.

*Tokcan, H. (2007). Sosyal bilgiler öğretiminde bütünsel beyin yaklaşımının akademik başarı üzerine etkisi. Türkiye Sosyal Araştırmalar Dergisi, 11(3), 51-64.

*Torun, F. ve Duran, H. (2014). Çocuk hakları öğretiminde oyun yönteminin başarıya, kalıcılığa ve tutuma etkisi. Adlyaman Üniversitesi Sosyal Bilimler Enstitüsü Dergisi, 7(16), 418448.

*Tran, V. D. ve Lewis, R. (2012). Effects of cooperative learning on students at an Giang University in Vietnam. International Education Studies, 5(1), 86-99. doi:10.5539/ies. v5n1p86.

*Tran, V. D. (2014). The effects of cooperative learning on the academic achievement and knowledge retention. International Journal of Higher Education, 3(2), 131. doi:10.5430/ijhe.v3n2p131.

*Tuna, F. (2013). Ortaöğretim coğrafya öğretiminde kavram ağı yönteminin öğrencilerin başarısına etkisi ve öğrencilerin yöntem hakkındaki görüşleri. Kastamonu Eğitim Dergisi, 21(3), 985-996.

*Turaçoğlu, İ., Alpat, Ş. ve Ellez, A. M. (2013). Effects of Jigsaw on Teaching Chemical Nomenclature. Education \& Science, 38(167), 256-272.

*Türksoy, E. ve Taşlıdere, E. (2016). Aktif öğrenme teknikleri ile zenginleştirilmiş öğretim yönteminin 5. sınıf öğrencilerinin fen ve teknoloji dersi akademik başarı ve tutumları üzerine etkisi. Ahi Evran Üniversitesi Kırşehir Ë̆itim Fakültesi Dergisi, 17(1), 57-77.

*Tüysüz, C., Tatar, E. ve Kuşdemir, M. (2010). Probleme dayalı öğrenmenin kimya dersinde öğrencilerin başarı ve tutumlarına etkisinin incelenmesi. Mustafa Kemal Üniversitesi Sosyal Bilimler Enstitüsü Dergisi, 7(13), 48-55.

*Ulu, C. ve Bayram, H. (2015). Argümantasyon tabanlı bilim öğrenme yaklaşımına dayalı laboratuvar etkinliklerinin 7. sınıf öğrencilerinin kavram öğrenmelerine etkisi: Yaşamımızdaki elektrik ünitesi. Ege Eğitim Dergisi, 16(2), 316-343.

*Ulubey, Ö. ve Gözütok, F. D. (2015). Yaratıcı drama ve diğer etkileşimli öğretim yöntemleri ile geleceğin vatandaşlık, demokrasi ve insan hakları eğitimi. Education \& Science, 40(182), 87-109. doi:109. 10.15390/EB.2015.4845.

*Ünal, Ç. ve Çelikkaya, T. (2009). Yapılandırmacı yaklaşımın sosyal bilgiler öğretiminde başarı, tutum ve kalıc1lı̆ga etkisi (5. sınıf örneği). Atatürk Üniversitesi Sosyal Bilimler Enstitüsü Dergisi, 13(2), 1-19.

*Uyar, G. ve Bal, A. P. (2015). Altıncı sınıf öğrencilerinde probleme dayalı öğrenmenin akademik başarıya etkisi. Pegem Ĕgitim ve Öğretim Dergisi, 5(4), 361-374. doi:10.14527/pegegog.2015.020.

*Uzun, N. (2012). A sample of active learning application in science education: The thema "cell" with educational games. Procedia-Social and Behavioral Sciences, 46, 29322936. doi:10.1016/j.sbspro.2012.05.592

*Wong, K. K. H. ve Day, J. R. (2009). A comparative study of problem-based and lecture-based learning in junior secondary school science. Research in Science Education, 39(5), 625642. doi: 10.1007/s11165-008-9096-7

*Yalçın, Y. ve Kavcar, N. (2010). Su dalgaları konusunun öğretiminde işbirlikli öğrenme yönteminin öğrenci başarısına etkisi. Milli Ĕgitim Dergisi, 185, 193-226.

*Yalçınkaya, E., Taştan-Kırık, Ö., Boz, Y. ve Yıldıran, D. (2012). Is case-based learning an effective teaching strategy to challenge students' alternative conceptions regarding chemical kinetics? Research in Science \& Technological Education, 30(2), 151-172. doi:10.1080/02635143.2012.698605

*Yang, Y. T. C. ve Chang, C. H. (2013). Empowering students through digital game authorship: Enhancing concentration, critical thinking, and academic achievement. Computers \& Education, 68, 334-344. doi:10.1016/j.compedu.2013.05.023. 
*Yıldırım, B. ve Girgin, S. (2012). 8. sınıf kalıtım ünitesinin öğretilmesinde işbirlikli öğrenme yönteminin öğrenci başarısına ve bilginin kalıcılığına etkisi. İlköğretim Online, 11(4), 958-965.

*Yıldırım, K. ve Tarım, K. (2008). Çoklu zekâ kuramı destekli kubaşı öğrenme yönteminin ilköğretim beşinci sınıf matematik dersinde akademik başarı ve hatırda tutma düzeyine etkisi. Ilköğretim Online, 7(1), 174-187.

*Yu, W. C. W., Lin, C. C., Ho, M. H. ve Wang, J. (2015). Technology facilitated PBL pedagogy and its impact on nursing student's academic achievement and critical thinking dispositions. TOJET: The Turkish Online Journal of Educational Technology, 14(1), 97-107.

*Ziadat, A. H. ve Al Ziyadat, M. T. (2016). The effectiveness of training program based on the six hats model in developing creative thinking skills and academic achievements in the Arabic language course for gifted and talented Jordanian students. International Education Studies, 9(6), 150. doi:10.5539/ies.v9n6p150.

Adams, G. ve Carnine, D. (2003). Direct instruction. H. L. Swanson, K. R. Harris, ve S. Graham (Yay. haz.). Handbook of learning disabilities içinde (s. 403-416). New York: Guilford.

American Psychological Association. (1997). Learner-centered psychological principles: a framework for school redesign and reform. Erişim adresi: https://www.apa.org/ed/ governance/bea/learner-centered.pdf.

Armstrong, T. (2000). Multiple intellegences in the classroom. VA, USA: Association for Supervision ve Curriculum Development.

Asha, I. K. ve Al Hawi, A. M. (2016). The Impact of cooperative learning on developing the sixth-grade students' decision-making skill and academic achievement. Journal of Education and Practice, 7(10), 60-70.

Ayaz, M. F. ve Söylemez, M. (2015). The effect of the project-based learning approach on the academic achievements of the students in science classes in Turkey: A meta-analysis study. Education ve Science, 40(178), 255-283.

Ayaz, M. F. (2015). Probleme dayalı öğrenme yaklaşımının öğrencilerin fen derslerindeki akademik başarılarına etkisi: Bir meta-analiz çalışması. Turkish Studies-International Periodical for the Languages, Literature and History of Turkish or Turkic, 10(3), 139160. doi: 10.7827/TurkishStudies.7664.

Ayaz, M. F. ve Şekerci, H. (2015). Yapılandırmacı öğrenme yaklaşımının akademik başarıya ve tutuma etkisi: Bir meta-analiz çalışması. Hasan Ali Yücel Eğitim Fakültesi Dergisi, 12(2), 27-44.

Baş, G. ve Beyhan, Ö. (2010). Effects of multiple intelligences supported project-based learning on students' achievement levels and attitudes towards English lesson. International Electronic Journal of Elementary Education, 2(3), 365-386.

Benson, P. (2012). Learner-centered teaching. A. Burns ve J. C. Richards (Yay. haz.). The Cambridge guide to pedagogy and practice in second language teaching içinde (s. 3037). Cambridge, UK: Cambridge University Press.

Biçer, N. (2017). The influence of student-centered methods in Turkish language instruction on academic success: A meta-analysis study. Universal Journal of Educational Research, 5(4), 687-697. doi: 10.13189/ujer.2017.050419.

Borenstein, M., Hedges, L. V., Higgins, J. P. ve Rothstein, H. R. (2009). Introduction to metaanalysis. West Sussex: John Wiley ve Sons, Ltd.

Botts, D. C., Losardo, A. S., Tillery, C. Y. ve Werts, M. G. (2014). A comparison of activitybased intervention and embedded direct instruction when teaching emergent literacy skills. The Journal of Special Education, 48(2), 120-134. doi: 10.1177/002246691244 9652.

Brown, K. L. (2003). From teacher-centered to learner-centered curriculum: Improving learning in diverse classrooms. Education, 124(1), 49-54. 
Capar, G. ve Tarim, K. (2015). Efficacy of the cooperative learning method on mathematics achievement and attitude: A meta-analysis research. Educational Sciences: Theory and Practice, 15(2), 553-559. doi: 10.12738/estp.2015.2.2098.

Çarkungöz, E. ve Ediz, B. (2009). Meta analiz. Uludağ Üniversitesi Veteriner Fakültesi Dergisi, 28, 33-37.

Çelik, S. (2013). İlköğretim matematik derslerinde kullanılan alternatif öğretim yöntemlerinin akademik başarıya etkisi: Bir meta analiz çalı̧̧ması (Yayımlanmamış yüksek lisans tezi). Eskişehir Osmangazi Üniversitesi, Eskişehir.

Cheang, K. I. (2009). Effect of learner-centered teaching on motivation and learning strategies in a third-year pharmacotherapy course. American journal of pharmaceutical education, 73(3), 1-8.

Cornelius-White, J. (2007). Learner-centered teacher-student relationships are effective: A meta-analysis. Review of educational research, 77(1), 113-143. doi: 10.3102/ 003465430298563.

Dinçer, S. (2014). Ĕgitim bilimlerinde uygulamal meta-analiz. Ankara: Pegem Akademi Yayıncilik.

Dochy, F., Segers, M., Van den Bossche, P. ve Gijbels, D. (2003). Effects of problem-based learning: A meta-analysis. Learning and instruction, 13(5), 533-568. doi: doi:10.1016/ S0959-4752(02)00025-7.

Fink, L. D. (2016). Five high-impact teaching practices: A list of possibilities. Collected Essays on Learning and Teaching, 9, 3-18.

Gözüyeşil, E. (2012). Beyin temelli ögrenmenin akademik başartya etkisi: Bir meta analiz çalışması (Yayımlanmamış yüksek lisans tezi). Niğde Üniversitesi, Niğde.

Günter ve K1lınç-Alpat, S. (2017). The effects of problem-based learning (PBL) on the academic achievement of students studying 'Electrochemistry'. Chemistry Education Research and Practice, 18(1), 78-98. doi: 10.1039/c6rp00176a

Hattie, J. A. C. (2009). Visible learning: A synthesis of over 800 meta-analyses relating to achievement. New York, NY: Routledge.

Hedges, L. V. (1987). How hard is hard science, how soft is soft science? The empirical cumulativeness of research. American Psychologist, 42(5), 443-455.

Johnson, D. W., Johnson, R. T. ve Stanne, M. B. (2000). Cooperative Learning Methods: A Meta-Analysis. Erişim adresi: https://pdfs.semanticscholar.org/93e9/97fd0e883cf7cceb 3b1b612096c27aa40f90.pdf.

Kılınçaslan, H. ve Özdemir-Şimşek, P. (2015). Effects of curriculum layered and creative drama methods on 6th grade "force and motion" unit on achievement, attitude and retention. Education ve Science, 40(180), 217-245.

Klahr, D. ve Nigam, M. (2004). The equivalence of learning paths in early science instruction: Effects of direct instruction and discovery learning. Psychological science, 15(10), 661667.

Kyndt, E., Raes, E., Lismont, B., Timmers, F., Cascallar, E., ve Dochy, F. (2013). A metaanalysis of the effects of face-to-face cooperative learning. Do recent studies falsify or verify earlier findings? Educational Research Review, 10, 133-149. doi: 10.1016/j.edurev.2013.02.002.

Lazonder, A. W. ve Harmsen, R. (2016). Meta-analysis of inquiry-based learning: Effects of guidance. Review of Educational Research, 86(3), 681-718.

Marzano, R. J., Pickering, D. J. ve Pollock, J. E. (2001). Classroom instruction that works: Research-based strategies for increasing student achievement. Alexandria, VA: Association for Supervision and Curriculum Development.

McCombs, B. (2012). Developing Responsible and Autonomous Learners: A Key to Motivating Students. Erişim adresi: http://www.apa.org/education/k12 /learners.aspx.

McCombs, B. L. ve Whisler, J. S. (1997). The learner-centered classroom and school: Strategies for increasing student motivation and achievement. San Francisco: Jossey-Bass Inc., Publishers. 
McTighe, J. ve Wiggins, G. (1999). The understanding by design handbook. Alexandria, VA: Association for Supervision and Curriculum Development.

Morrison, G. R., Ross, S. M. ve Kemp, J. E. (2004). Designing effective instruction (4th ed.). New Jersey: John Wiley ve Sons.

Overby, K. (2011). Student-centered learning. ESSAI, 9(1), 32.

Özdemirli, G. (2011). İşbirlikli ögrrenme yönteminin ögrencinin matematik başarısı ve matematiğe ilişkin tutumu üzerindeki etkililiği: Bir meta-analiz çalı̧̧ması (Yayımlanmamış yüksek lisans tezi). Çukurova Üniversitesi, Adana.

Pedersen, S. ve Liu, M. (2003). Teachers' beliefs about issues in the implementation of a student-centered learning environment. Educational Technology Research and Development, 51(2), 57-76.

Rittle-Johnson, B. (2006). Promoting transfer: Effects of self-explanation and direct instruction. Child development, 77(1), 1-15.

Rivkin, S. G., Hanushek, E. A. ve Kain, J. F. (2005). Teachers, schools, and academic achievement. Econometrica, 73(2), 417-458.

Rizi, C. E., Najafipour, M., Haghani, F. ve Dehghan, S. (2013). The effect of the using the brainstorming method on the academic achievement of students in grade five in Tehran elementary schools. Procedia-Social and Behavioral Sciences, 83, 230-233. doi: 10.1016/j.sbspro.2013.06.045.

Savelsbergh, E. R., Prins, G. T., Rietbergen, C., Fechner, S., Vaessen, B. E., Draijer, J. M. ve Bakker, A. (2016). Effects of innovative science and mathematics teaching on student attitudes and achievement: A meta-analytic study. Educational Research Review, 19, 158-172. doi: 10.1016/j.edurev.2016.07.003.

Schroeder, C. M., Scott, T. P., Tolson, H., Huang, T. Y. ve Lee, Y. H. (2007). A meta-analysis of national research: Effects of teaching strategies on student achievement in science in the United States. Journal of research in science teaching, 44(10), 1436-1460. doi: $10.1002 /$ tea.20212.

Schunk, D. H. (2012). Learning theories: An educational perspective (6th ed.). Boston, MA: Allyn ve Bacon.

Schwartz, D. L. ve Bransford, J. D. (1998). A time for telling. Cognition and instruction, 16(4), 475-5223. doi: 10.1207/s1532690xci1604_4.

Semerci, Ç. ve Batdi, V. (2015). A meta-analysis of constructivist learning approach on learners' academic achievements, retention and attitudes. Journal of Education and Training Studies, 3(2), 171-180. doi:10.11114/jets.v3i2.644.

Şen, Ş. ve Yılmaz, A. (2013). İşbirlikçi öğrenmenin kavramsal değişim üzerindeki etkisi: Bir meta analiz çalışması. Karaelmas Eğitim Bilimleri Dergisi, 1, 21-32.

Senemoğlu, N. (2007). Gelişim ögrenme ve ögretim: Kuramdan uygulamaya. Ankara: Gönül Yayinc1lik.

Silberman, M. (2016). Aktif ögrretim: Sinıflarda ögrenmeyi harekete geçirecek sekiz adım ve 32 strateji, N. Kalaycı (Çev. ed.). Ankara: Pegem Akademi Yayıncılık. (Orijinal çalışma 1996 yılında yayımlanmıştır)

Sönmez, V. (2009). Ögretim ilke ve yöntemleri (3. bs.). Ankara: Anı Yayınc1lık.

Springer, L., Stanne, M. E. ve Donovan, S. S. (1999). Effects of small-group learning on undergraduates in science, mathematics, engineering, and technology: A meta-analysis. Review of educational research, 69(1), 21-51.

Tarım, K. (2003). Kubaşık ögrenme yönteminin matematik ögretimindeki etkinliği ve kubaşık öğrenme yöntemine ilişkin bir meta analiz çalı̧̧ması (Yayımlanmamış doktora tezi). Çukurova Üniversitesi, Adana.

Thalheimer, W. ve Cook, S. (2002). How to calculate effect sizes from published research: A simplified methodology. Work-Learning Research, 1-9. Erişim adresi: http://www.bwgriffin.com/gsu/courses/edur9131/content/Effect_Sizes_pdf5.pdf. 
Thoron, A. C. ve Myers, B. E. (2012). Effects of Inquiry-based Agriscience Instruction on Student Scientific Reasoning. Journal of Agricultural Education, 53(4), 156-170. doi: 10.5032/jae.2012.04156.

Tok, Ş. (2009). Öğrenme-öğretme strateji ve modelleri. A. Doğanay (Yay. haz.), Öğretim ilke ve yöntemleri içinde (s. 130-157). Ankara: Pegem Akademi Yayıncılık.

Topan, B. (2013). Matematik ögretiminde ögrrenci merkezli yöntemlerin akademik başarı ve derse yönelik tutum üzerindeki etkililiği: Bir meta-analiz çalışması (Yayımlanmamış yüksek lisans tezi). Kocaeli Üniversitesi, Kocaeli.

Tran, V. D. ve Lewis, R. (2012). Effects of cooperative learning on students at an Giang University in Vietnam. International Education Studies, 5(1), 86-99. doi:10.5539/ies. v5n1p86.

Tuncer, M. ve Dikmen, M. (2017). İşbirlikli öğrenmenin başarıya etkisi: Çalışma grubu ile etki büyüklüğü arasındaki ilişkiye dair bir meta analiz çalışması. Journal of Human Sciences, 14(1), 473-485. doi:10.14687/jhs.v14i1.4314.

Ural, G. ve Bümen, N. (2016). A meta-analysis on instructional applications of constructivism in science and technology teaching: A sample of Turkey. Education and Science, 41(185), 51-82.

Üstün, U. ve Eryılmaz, A. (2014). Etkili araştırma sentezleri yapabilmek için bir araştırma yöntemi: Meta-analiz. Ĕgitim ve Bilim, 39(174), 1-32.

Vernon, D. T. ve Blake, R. L. (1993). Does problem-based learning work? A meta-analysis of evaluative research. Academic medicine, 68(7), 550-63.

Weimer, M. (2002). Learner-centered teaching: Five key changes to practice. San Francisco: John Wiley ve Sons.

Yang, Y. T. C. ve Chang, C. H. (2013). Empowering students through digital game authorship: Enhancing concentration, critical thinking, and academic achievement. Computers ve Education, 68, 334-344. doi: 10.1016/j.compedu.2013.

Yaşar, Ş., Çengelci-Köse, T., Göz, N. L. ve Gürdoğan-Bayır, Ö. (2015). Sosyal bilgiler dersinde öğrenci merkezli öğretme-öğrenme süreçlerinin etkililiği: bir meta analiz çalışması. Anadolu Journal of Educational Sciences International, 5(1), 38-56.

Zhou, J., Zhou, S., Huang, C., Xu, R., Zhang, Z., Zeng, S., Ü. ve Qian, G. (2016). Effectiveness of problem-based learning in Chinese pharmacy education: A meta-analysis. BMC Medical Education, 16(1), 23. doi: 10.1186/s12909-016-0546-z.

\section{Extended Abstract \\ Introduction}

A curriculum structured by the requirements of this century is expected to guide the students in the process of understanding, practicing and producing new knowledge. It is stated that in this process, the teacher should offer appropriate opportunities for the acquisition of inquiry, critical and creative thinking, problem-solving, metacognitive skills and socio-emotional skills (Fink, 2016; Marzano et al., 2001; McCombs, 2012; Overby, 2011; Silberman, 1996/2016). In this context, it is observed that student-centered strategies, methods, and techniques providing active participation of the students in the process have been used and examined in various researches (Asha \& Hawi, 2016; Baş \& Beyhan, 2010; Günter \& K1lınç-Alpat, 2017; Hang Wong \& Day, 2008; Kılınçaslan \& Şimşek, 2015; Rizi et al., 2013; Thoron \& Myers, 2011; Tran \& Lewis, 2012; Yang \& Chang, 2013).

While the results of the research present critical data on the effects of student-centered strategies, methods, and techniques, it is suggested that the general tendency in educational research should be carried out (Hattie, 2009; Hedges, 1987). In other words, it is asserted that the results of a single study or a small set of studies can not decide whether a strategy or approach serves well, and the synthesized results of the findings should be acknowledged as the best-known results of the topic (Marzano et al., 2001). 
The aim of this study is to determine the effect of student-centered strategies, methods, and techniques on the academic achievement as they have been applied in different studies. In response to this aim, the following questions are proposed:

- Which student-centered strategies, methods, and techniques were used to improve academic achievement?

- What is the effect of student-centered strategies, methods, and techniques on the academic achievement of students when compared to the teacher-centered approaches?

- What are the factors that cause different levels of effect size?

\section{Method}

Meta-analysis method was used in this study. The scope of the study involves published articles between 2007-2016 in the journals of TR Directory, ERIC and Social Science Citation Index databases. All of them concern the effects of student-centered strategies, methods, and techniques on the academic achievement. "Teaching methods, teaching strategies, teaching techniques and academic achievement" in Turkish and their English equivalents in quotes and non-quoted were examined as the keywords in the databases to reach the publications. The databases were first searched on May 25, 2016, and researched on February 15, 2017, for necessary controls.

As a result of this process, 126 experimental studies aiming to determine the effect of student-centered strategies, methods, and techniques on the academic achievement in comparison to the teacher-centered strategies, methods, and techniques were reached. However, those which did not meet the meta-analysis inclusion criteria were excluded. In this respect, 21 studies with no standard deviations or inequitable pre-test scores were excluded from the analysis. As a result, 105 studies were included in the analysis, and from those studies, a total of 120 effect size coefficients were calculated. To analyze the data, one of the meta-analysis software was preferred, and the effect size coefficients were calculated according to Hedges g. Statistical software was used for some descriptive statistics. For the interpretation of the calculated effect size coefficients, the classification proposed by Thalheimer and Cook (2002) was used.

\section{Results and Discussion}

When the results of the analysis are evaluated holistically, it has been seen that it is the cooperative learning method that has frequently been used to increase academic achievement (f:37) and that the student-centered strategies, methods, and techniques mostly have medium (f:29), large (f: 30) and enormous level (f:34) effect on the academic achievement. As a result of the heterogeneity test, the Q-value was found to be 1039.166 , and the p-value was 0.00 . Since the Q-value in the table $\chi^{2}$ is 146.56 for the 119 degrees of freedom (df) and 95\% level of significance, it is agreed that the nature of the studies is heterogeneous. For this reason, the random effect model was used as the analysis model, and the overall effect size was calculated as 1.14 within the limits of 1.006 to 1.266 . When effect size is interpreted, it is found that student-centered strategies, methods, and techniques have a very large effect on the academic achievement in comparison to the teacher-centered approaches. These findings show that the student-centered strategies, methods, and techniques used in different fields enhance the academic achievement of the students.

In similar studies, it is seen that cooperative learning method is the most studied method in the field (Çelik, 2013; Yaşar et al., 2015), and the results show that student-centered practices have large (Çelik, 2013; Marzano et al., 2001; Semerci \& Batdi, 2015; Topan, 2013; Ural \& Bümen, 2016) and very large effect (Ayaz \& Şekerci, 2015; Yaşar et al., 2015) on the academic achievement supporting the findings of this research. It is seen that other results supporting the results of the research are gathered from the meta-analysis studies conducted on individual effects of student-centered strategies, methods, and techniques. In these researches, cooperative learning (Biçer, 2017; Capar \& Tarım, 2015; Hattie, 2009; Jonhnson, Johnson \& Stanne, 2000; 
Kyndt et al., 2013; Savelsbergh et al., 2016; Schroeder et al., 2007; Springer et al., 1999; Şen \& Y1lmaz, 2013; Tarım, 2003; Tuncer \& Dikmen, 2017), problem-based learning (Ayaz, 2015; Vernon \& Blake 1993; Zhou et al., 2016) and project-based learning (Ayaz \& Söylemez, 2015) were found to be more efficient in increasing academic achievement when compared to the teacher-centered approaches.

In addition to this, studies conducted at secondary and tertiary level were commonly found to have a higher level of effect. In similar meta-analysis studies, it has been determined that student-centered methods such as cooperative learning (Capar \& Tarım, 2015; Özdemirli, 2011; Tarım, 2003), project-based learning (Ayaz \& Söylemez, 2015), and brain-based learning (Gözüyeşil, 2012) are more effective on the academic achievement of secondary and higher education students. This result indicates, depending on the age of students, the preliminary knowledge, skills, and attitudes related to the subject are crucial variables to be taken into consideration in using student-centered strategies, methods, and techniques.

As a result, it was determined that student-centered strategies, methods, and techniques are more effective in increasing the academic achievement in different courses when compared to the teacher-centered approaches and that this effect is very large. Nevertheless, it was revealed that the structure of the studied subject, the characteristics of the measurement instrument, and the student-derived variables that need to be controlled differentiated the effect size levels. 